Check for updates

Cite this: RSC Adv., 2018, 8, 20517

Received 5th April 2018

Accepted 9th May 2018

DOI: $10.1039 / c 8 r a 02941 e$

rsc.li/rsc-advances

\section{Synthesis of sulfamic acid supported on Cr-MIL-101 as a heterogeneous acid catalyst and efficient adsorbent for methyl orange dye}

\author{
Sohier A. El-Hakam, ${ }^{a}$ Salem E. Samra, ${ }^{a}$ Shady M. El-Dafrawy, ${ }^{a}$ Amr A. Ibrahim, ${ }^{a}$ \\ Reda S. Salama (iD) ${ }^{* b}$ and Awad I. Ahmed ${ }^{a}$
}

Typical highly porous metal-organic framework (MOFs) materials based on chromium benzenedicarboxylates $(\mathrm{Cr}$-BDC) were prepared through a one-pot hydrothermal synthesis, and were then modified by loading the appropriate ratio of sulfamic acid (SA) using a simple impregnation technique. Pure and modified MIL-101 was characterized by XRD, TEM, SEM and FT-IR measurements. TEM and SEM measurements confirmed that the MIL-101 particles preserved their regular octahedral structure after loading with different weight contents of sulfamic acid. The total number of acid sites and Brønsted to Lewis acid sites ratio $(B / L)$ were examined using potentiometric titration and pyridine adsorption. The acid strength and surface acidity of SA/MIL-101 gradually increased after the modification of Cr-MIL-101 by sulfamic acid crystals up to $55 \mathrm{wt} \%$, then decreased again. The catalytic performance of the solid catalysts was confirmed in the synthesis of 14-phenyl-14H-dibenzo [a,j] xanthene and 7-hydroxy-4-methyl coumarin. In the two reactions, the sample with 55\% sulfamic acid loaded on MIL-101 displayed the highest catalytic activity and acidity. The adsorption behaviors of sulfamic acid loaded on MIL-101 materials for methyl orange (MO) as an anionic dye were studied, and were exceptionally suitable for the Langmuir adsorption isotherm. All loaded adsorbents showed high adsorption capacity for methyl orange at $25^{\circ} \mathrm{C}$. The results indicate that the adsorption capacity was modified by changing the amount of sulfamic acid loaded on MIL-101.

\section{Introduction}

One of the most vital features of green chemistry is the effective use of renewable resources, the removal of waste and the avoidance of polluting and toxic solvents and reagents in the production and application of chemical products. Nowadays, heterogeneous catalysts are attracting much more attention than homogeneous catalysts in synthetic organic chemistry because of the numerous advantages of these materials compared to homogeneous catalysts; e.g., the facility of recovery, good reproducibility and reusability. ${ }^{1}$ The substitution of liquid acid catalysts, which are corrosive, toxic and difficult to recover from the reaction mixture, with efficient solid materials could support the goal of catalysis in the removal of risky substances.

Metal-organic frameworks (MOFs) are a class of highly crystalline porous hybrid materials that are prepared from the coordination of metal clusters or ions as nodes with polyfunctional organic ligands as linkers to form infinite 1, 2 or 3-

${ }^{a}$ Chemistry Department, Faculty of Science, Mansoura University, Mansoura, Egypt ${ }^{b}$ Basic Science Department, Faculty of Engineering, Delta University for Science and Technology, Gamasa, Egypt. E-mail: reda.salama@deltauniv.edu.eg; dr.reda. salama@gmail.com; Tel: +20-1061391656 dimensional frameworks; ${ }^{2-4}$ they are also known as porous coordination polymers (PCPs). MOFs have attracted much attention in the last few years because of their incredible properties, which include high structure porosity exhibiting large specific surface area (up to several thousand $\mathrm{m}^{2} \mathrm{~g}^{-1}$ ), high pore volume (up to $90 \%$ of the crystal volume) and low framework density. ${ }^{5-10}$ These properties allow MOFs to have potential applications in separation processes and gas storage, ${ }^{\mathbf{1 1}}$ sensor technology, ${ }^{12,13}$ catalysis, ${ }^{14}$ ion exchange,${ }^{15}$ drug delivery, ${ }^{16}$ and luminescence. ${ }^{\mathbf{1 7}}$

One of the various MOFs is chromium(III) terephthalate, also known as Cr-MIL-101 (MIL for Material of Institute Lavoisier), which has suitable resistance to high temperatures up to $300{ }^{\circ} \mathrm{C}$ and solubility in water and common solvents. ${ }^{18-20}$ Cr-MIL-101 is fabricated from chromium trimeric octahedral clusters and carboxylate moieties (terephthalic acid) that offer a unique high surface area, and it has a rigid zeotype crystal structure with two types of quasi-spherical cages with diameter of 2.9 and $3.4 \mathrm{~nm}$ accessible through window sizes at about 1.2 and $1.6 \mathrm{~nm}$, respectively. (The smaller cages have pentagonal windows, while the larger cages are related to both hexagonal and pentagonal windows). ${ }^{21}$ Additionally, coordinatively unsaturated sites (CUS) with relatively mild Lewis acid properties exist due to the presence of chromium clusters that are not attached 
to the organic linkers. ${ }^{22}$ The acidic CUS sites and two types of large cavities permit the post-synthesis modification of MIL-101 with active species such as nano-particles (NPS), organic molecules, polyoxometalates (POM) and superacids. These could potentially improve the Brønsted acid, Lewis acid, and redox sites for a range of acid-catalyzed and redox reactions including hydrogenation, ${ }^{23}$ esterification, ${ }^{24,25}$ as well as epoxidation reactions. ${ }^{26}$

The absence of functional groups and selective sites in most of the stable metal-organic frameworks has limited the use of MOFs in applications such as catalysis. In order to functionalize MOFs with various active sites including heteropoly acids, mineral acids or metal nanoparticles have been loaded into MIL-101 using different methods. ${ }^{27-31}$ One of the best low-cost, green and effective acids is sulfamic acid $\left(\mathrm{NH}_{2} \mathrm{SO}_{3} \mathrm{H}\right)$, which is commercially available and popularly utilized as an effective catalyst in organic synthesis. ${ }^{32,33}$

Xanthenes, especially 14-phenyl-14H-dibenzo [a,j] xanthene, have received much attention from the pharmaceutical manufacturing industry. This is because they have a great range of pharmacological and biological features like anti-inflammatory, ${ }^{34}$ antiviral, ${ }^{35}$ antibacterial and antifungal ${ }^{36}$ activities, in addition to their use in photodynamic therapy, ${ }^{37}$ dyes, ${ }^{38}$ visualization of biomolecules using $\mathrm{pH}$-sensitive fluorescent materials ${ }^{39}$ and utility in laser technologies ${ }^{\mathbf{4 0}}$ due to their interesting spectroscopic properties. Xanthenes are synthesized by the condensation reaction of aromatic aldehydes with $\beta$-naphthol in the presence of acid catalysts like heteropoly acid supported MCM-41, ${ }^{41}$ boric acid, ${ }^{42}$ silica bonded $N$-propyl sulfamic acid ${ }^{43}$ and succinimide- $N$-sulfonic acid. ${ }^{44}$

Coumarin and its derivatives attract major interest due to their significance in synthetic organic chemistry. Numerous products that contain the coumarin nucleus act as the bases for several biological activities such as antispasmodic, diuretic, anticoagulant, antibacterial and anticarcinogenic. ${ }^{45,46}$ These compounds were prepared by the Pechmann condensation in the presence of acid catalysts like sulfated titania supported on MCM-41, ${ }^{47}$ nanostructured sulfated tin oxide ${ }^{48}$ and tungstophosphoric acid supported mesoporous zirconia. ${ }^{49}$

Pigments and dyes attract great interest in the manufacturing industry. ${ }^{50}$ The release of these dyes into water has caused global concern because of their overall environmental risks. ${ }^{51}$ Additionally, numerous dyes are very poisonous to many organisms and cause direct damage to aquatic communities. Among the reasons dye decomposition is difficult is the high stability of dyes to oxidation and light. ${ }^{52}$ In order to remove dye materials from polluted water, numerous chemical, physical and biological methods have been examined. Among the proposed methods, the adsorption technique is considered to be the most popular method for dye removal due to its being remove several coloring materials simultaneously and it does not require high temperatures. ${ }^{53}$

One of the most popular anionic/acidic dyes is methyl orange (MO), which we used to examine the adsorption properties of our modified and unmodified MIL-101. Methyl orange is used in printing, dyeing textiles, dyestuff and so on ${ }^{53}$ and it is also used in the acid-base titration of mineral acids and strong bases as an indicator. Methyl orange is considered as an azo dye as it contains the azo group $(\mathrm{N}=\mathrm{N})$ in its structure. These types of azo dyes are the most frequently used dyes; they are not highly toxic but may cause allergies and hypersensitivity. ${ }^{54}$

In recent work, MIL-101 was synthesized with different contents of sulfamic acid using the impregnation technique. The physiochemical properties of the resulting catalysts were identified by several techniques such as XRD, SEM, TEM, Fourier transform-IR, non-aqueous titration with $n$-butylamine and pyridine adsorption. The catalytic activities of the prepared solid acid samples were examined by using them as catalysts for the synthesis of 7-hydroxy-4-methyl coumarin and the synthesis of 14-phenyl-14H-dibenzo [ $a, j]$ xanthene. However, so far, there have been a few reports on the usage of MIL-101 in the adsorption of methyl orange. Due to the high nitrogen content, the adsorption behaviors of the modified MIL-101 materials were determined for removing methyl orange from water.

\section{Experimental}

\subsection{Materials}

All inorganic and organic chemicals used in the synthesis of catalysts are commercially available (Merck) and were used without further purification: $N, N$-dimethylformamide $\left(\left(\mathrm{CH}_{3}\right)_{2}\right.$ $\mathrm{NCHO})$, ethanol $\left(\mathrm{C}_{2} \mathrm{H}_{5} \mathrm{OH}\right)$, terephthalic acid $\left(\mathrm{C}_{6} \mathrm{H}_{4}(\mathrm{COOH})_{2}\right)$, sulfamic acid $\left(\mathrm{NH}_{2} \mathrm{SO}_{3} \mathrm{H}\right)$ and chromium trinitrate $\left(\mathrm{Cr}\left(\mathrm{NO}_{3}\right)_{3}\right.$ $\left.\cdot 9 \mathrm{H}_{2} \mathrm{O}\right)$.

\subsection{Preparation of MIL-101 (Cr)}

Cr-MIL-101 was prepared as reported previously, with slight modification. ${ }^{55}$ A mixture of $\mathrm{Cr}\left(\mathrm{NO}_{3}\right)_{3} \cdot 9 \mathrm{H}_{2} \mathrm{O}$ (2000 mg, 2.0 $\mathrm{mmol}$ ), 1,4-benzene dicarboxylic acid (TPA) (830 mg, $2.0 \mathrm{mmol}$ ) and distilled water $(24 \mathrm{~mL})$ was sonicated until a dark blue suspension was formed, the suspension was transferred into a Teflon-lined autoclave bomb and placed in an oven for $8 \mathrm{~h}$ at $220^{\circ} \mathrm{C}$. After cooling, the suspension was centrifuged to isolate the green powder of MIL-101 and the resulting product was soaked in $\mathrm{N}, \mathrm{N}$-dimethylformamide for one day to remove unreacted terephthalic acid encapsulated inside the pores, then the solid product was washed with DMF and hot ethanol, filtered off and finally dried in an oven at $150{ }^{\circ} \mathrm{C}$ for $5 \mathrm{~h} .{ }^{56}$

Sulfamic acid loaded on MIL-101 was prepared by the direct impregnation method, in which $1 \mathrm{~g}$ of the as synthesized MIL101 was suspended in $20 \mathrm{~mL}$ of aqueous solution with different weight percentages of sulfamic acid (15\%, 25\%, 40\%, $55 \%, 70 \%, 85 \% \mathrm{SA} / \mathrm{MIL}-101)$ under vigorous stirring for $4 \mathrm{~h}$ and impregnated for one day. The product was filtered, washed, and dried at $100{ }^{\circ} \mathrm{C}$ overnight. Then, $55 \mathrm{wt} \%$ of SA/MIL-101 was calcined in a muffle furnace in air at calcination temperatures of 150,250 and $350{ }^{\circ} \mathrm{C}$ for 4 hours at a rate of $5{ }^{\circ} \mathrm{C}$ per minute.

\subsection{Catalyst characterization}

2.3.1 XRD measurements. X-ray powder diffraction (XRD) studies of the various materials were conducted at low and high angle using a PW 150 (Philips) with Ni filtered $\mathrm{Cu} \mathrm{K} \alpha$ radiation $(\lambda=1.540 \AA)$, operated at $40 \mathrm{kV}$ and $30 \mathrm{~mA}$. The scanning was 
completed for $2 \theta$ angles from 1 to 80 , with a step time of $2 \mathrm{~s}$ and a step size of 0.02 .

2.3.2 FTIR spectroscopic studies. FT-IR spectra of all materials were detected using the Perkin-Elmer system 2000 with a $4 \mathrm{~cm}^{-1}$ resolution and 128 scans in the middle IR region $400-4000 \mathrm{~cm}^{-1}$. The materials were mixed with $\mathrm{KBr}$ and pressed into $3 \mathrm{~mm}$ diameter self-supporting discs.

2.3.3 SEM and TEM images. The morphologies of the samples were examined using a Jeol JSM-6510LV scanning electron microscope (SEM). TEM images and particle size were determined using a Jeol JEM-2100. For TEM images, the sample powder was sonicated in methanol for $30 \mathrm{~min}$ until dispersion, and a drop of the suspension was placed onto the carbon-coated copper grids.

2.3.4 BET measurements. $\mathrm{N}_{2}$ adsorption-desorption isotherms were measured at $77 \mathrm{~K}$ with liquid nitrogen on a BELSORP-mini II high precision surface area and pore size analyzer. The specific surface area was calculated using the Brunauer-Emmett-Teller (BET) equation. ${ }^{57}$ Pore volume and mean pore diameter were determined by Barrett-JoynerHalenda (BJH) equations. ${ }^{58}$

\subsubsection{Surface acidity studies}

2.3.5.1 Non-aqueous titration. Measurements of acid strength and the total acidity of solid materials were reported using potentiometric titration. ${ }^{47}$ The activated catalysts $(0.1 \mathrm{~g})$ were suspended in $10 \mathrm{~mL}$ acetonitrile for $2 \mathrm{~h}$. Then, the suspension was titrated with $0.05 \mathrm{~N} n$-butylamine in acetonitrile. The Orion 420 digital model was used to measure the electrode potential variation using a double junction electrode.

2.3.5.2 FTIR spectra of chemisorbed pyridine. Brønsted and Lewis acid sites existing on the material surfaces were detected by FT-IR spectra of chemisorbed pyridine. About $0.1 \mathrm{~g}$ of the samples was degassed at $200{ }^{\circ} \mathrm{C}$ for $3 \mathrm{~h}$ under high vacuum and then the samples were cooled to $30{ }^{\circ} \mathrm{C}$. The dry pyridine was then flashed inside the vacuum system and the samples were maintained under these conditions for one month. The excess pyridine was removed by evaporation at $70{ }^{\circ} \mathrm{C}$ (ref. 59) then the samples were analyzed using a Perkin-Elmer system 2000 FT-IR spectrophotometer at $1400-1700 \mathrm{~cm}^{-1}$ after mixing $0.005 \mathrm{~g}$ of the sample with $0.1 \mathrm{~g} \mathrm{KBr}$ to make $30 \mathrm{~mm}$ diameter selfsupporting discs.

\subsubsection{Catalytic studies}

2.3.6.1 The synthesis of 14-phenyl-14H-dibenzo [a,j] xanthene. In a typical experiment, a mixture of $\beta$-naphthol $(2 \mathrm{mmol})$, benzaldehyde $(1 \mathrm{mmol})$, and catalyst $(50 \mathrm{mg})$ were added in a $25 \mathrm{~mL}$ round bottom flask and heated at $120{ }^{\circ} \mathrm{C}$ in an oil bath. After the reaction was completed (monitored by TLC), the product was dissolved in chloroform and filtered off by a simple filtration process to recover the catalyst and the crude solid product was purified by recrystallization in ethanol to produce pure 14-phenyl-14H-dibenzo $[a, j]$ xanthene, which was identified by FT-IR and melting point.

2.3.6.2 The synthesis of 7-hydroxy-4-methyl coumarin. A mixture of resorcinol $(1.1 \mathrm{~g}, 10 \mathrm{mmol})$ and ethyl acetoacetate $(2.5 \mathrm{~mL}, 20 \mathrm{mmol})$ was placed in a $25 \mathrm{~mL}$ round bottom flask, followed by catalyst powder and was activated at $120^{\circ} \mathrm{C}$ for $2 \mathrm{~h}$. The flask was placed in an oil bath and refluxed at $120^{\circ} \mathrm{C}$ for $2 \mathrm{~h}$.
The resultant mixture was filtered and poured into a $50 \mathrm{~mL}$ beaker containing crushed ice. The product was characterized by FT-IR spectroscopy and melting point.

2.3.7 Adsorption studies. Adsorption studies of pure and modified MIL-101 adsorbents were conducted by the addition of $0.05 \mathrm{~g}$ of adsorbent into a $50 \mathrm{~mL}$ solution of methyl orange and the bottle was shaken for $2 \mathrm{~h}$. The $\mathrm{pH}$ of the suspension was adjusted to 2 using $0.1 \mathrm{M} \mathrm{HCl}$ and $0.1 \mathrm{M} \mathrm{NaOH}$ solution.

The concentration of MO adsorbed at equilibrium $\left(q_{\mathrm{e}}\right.$ in $\mathrm{mg}$ $\mathrm{g}^{-1}$ ), was calculated from the equation

$$
q_{\mathrm{e}}=\frac{\left[\left(C_{\mathrm{o}}-C_{\mathrm{e}}\right) V\right]}{\mathrm{wt}}
$$

where, $C_{\mathrm{e}}$ and $C_{\mathrm{o}}$ are the equilibrium and initial concentrations of $\mathrm{MO}\left(\mathrm{mg} \mathrm{L}^{-1}\right)$, respectively, wt $(\mathrm{g})$ is the modified MIL-101 weight and $V(\mathrm{~L})$ is the volume of MO solution $(50 \mathrm{~mL})$.

\section{Results and discussion}

\subsection{X-ray diffraction pattern (XRD)}

The XRD patterns of the as synthesized MIL-101 and modified MIL-101 with various sulfamic acid contents are shown in Fig. 1 and 2. All samples displayed good crystallinity through the intensity of the peaks and agreed with the previously published XRD patterns for MIL-101. ${ }^{60}$ The main diffraction peaks of pure MIL-101 were at $2 \theta$ of $3.14^{\circ}, 5.17^{\circ}, 8.40^{\circ}, 9.25^{\circ}$ and $16.49^{\circ}$, which were found to be similar to the standard data for MIL-101. ${ }^{61}$ Low angle XRD patterns of the various materials illustrated in Fig. 1(X), demonstrated that there were no notable changes in the intensity of the peaks of the original MIL-101 material and the modified samples of MIL-101 by sulfamic acid. This approach is in agreement with the results of Ferey et al. ${ }^{21}$

The wide-range XRD patterns were obtained by scanning the samples from 5 to 80 degrees as presented in Fig. 1(Y), which displays a number of strong and sharp peaks at $2 \theta=20.3^{\circ}$, $25.3^{\circ}, 28.2^{\circ}, 37.5^{\circ}, 40.5^{\circ}, 43.2^{\circ}, 51.4^{\circ}$ and $63.7^{\circ}$, reflecting wellcrystallized sulfamic acid crystals. ${ }^{\mathbf{6 2 , 6 3}}$ The intensities of these peaks increased with increasing the sulfamic acid content; the peaks at $2 \theta$ of $25.3^{\circ}$ and $28.2^{\circ}$ also became more obvious at $85 \%$ SA/MIL-101. These results show that the sulfamic acid was well dispersed on Cr-MIL-101.

The diffraction patterns corresponding to samples of $55 \mathrm{wt} \%$ SA/MIL-101 calcined at $150^{\circ}, 250^{\circ}, 350^{\circ} \mathrm{C}$ are shown in Fig. 2 . As the calcination temperature increased, the intensities of the main peaks decreased and there was some shifting in the peak positions, which may be related to the decomposition of sulfamic acid at higher temperature and the evolution of $\mathrm{SO}_{3}$ from sulfamic acid bound to the Cr-MIL-101 surface. ${ }^{47}$

\subsection{FT-IR spectra}

FT-IR is an efficient analytical technique for confirming the presence of functional groups. Fig. 3 shows the FTIR spectra of pure and modified MIL-101 of the spectrum of Cr-MIL-101 in Fig. 3a indicates that there are sharp peaks in the range of 1400$1600 \mathrm{~cm}^{-1}$ that are related to the stretching mode vibration of $(\mathrm{C}=\mathrm{C})$ bound to the aromatic rings. Weak and narrow bands at 1017 and $749 \mathrm{~cm}^{-1}$ are related to the $\delta(\mathrm{C}-\mathrm{H})$ and $\gamma(\mathrm{C}-\mathrm{H})$ 

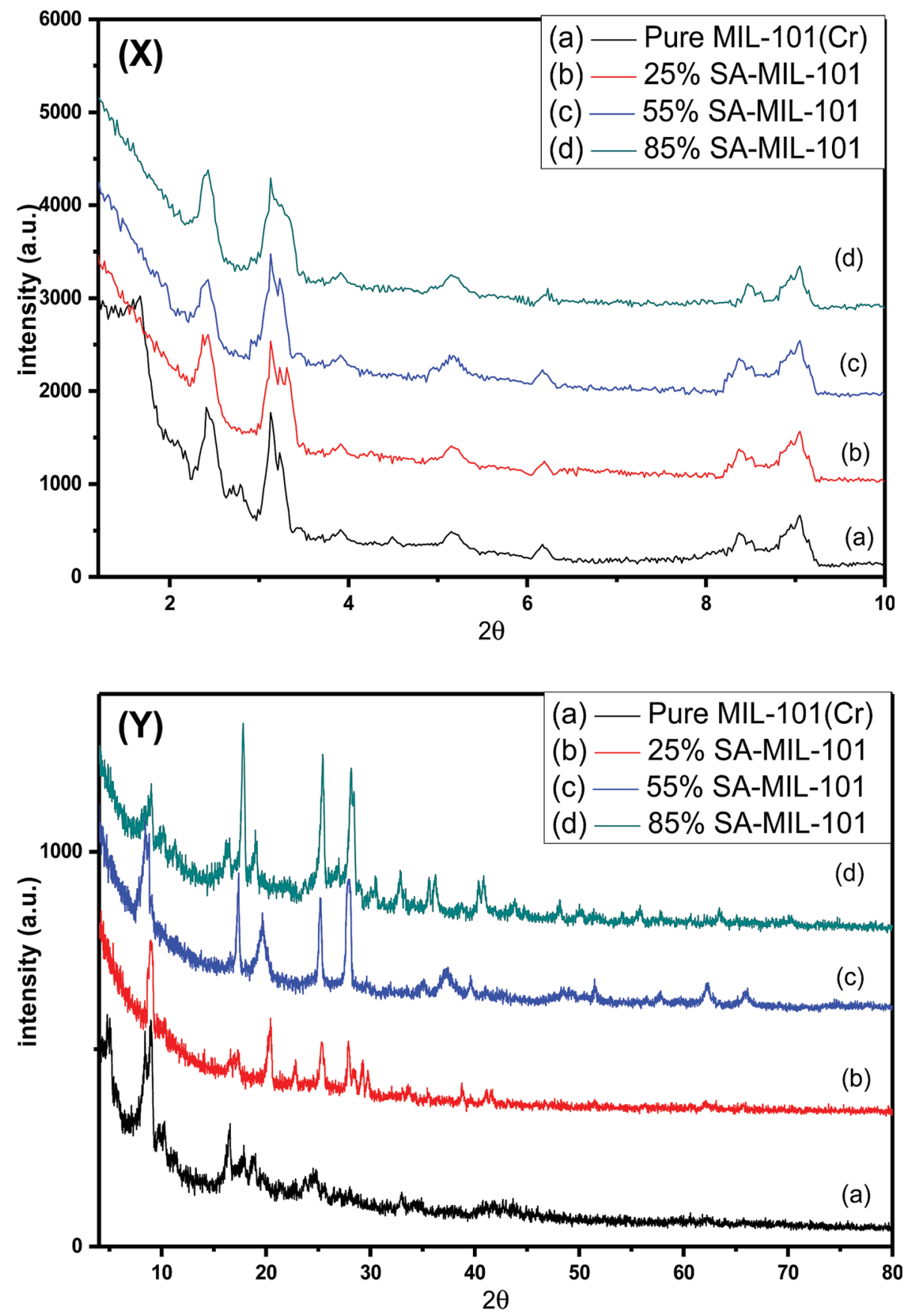

Fig. 1 (X) Low angle and (Y) high angle X-ray diffraction patterns of (a) Cr-MIL-101, (b) 25\% SA@MIL-101, (c) 55\% SA@MIL-101 and (d) 85\% SA@MIL-101.

vibrations of aromatic rings, respectively; the existence of aromatic rings shows that the organic ligand (linker) is present in the final product. The weak peaks in the spectral range of $400-700 \mathrm{~cm}^{-1}$ are most likely because of the out plane and inplane bending modes of carboxylic $\left(\mathrm{COO}^{-1}\right)$ groups. ${ }^{61}$ The strong peak at $1626 \mathrm{~cm}^{-1}$ is due to the vibration of the $(\mathrm{C}=\mathrm{O})$ group, while the broad peaks in the spectral range of 2400-3400 may be due to crystalline water or acidic $\mathrm{OH}$ of carboxylic groups. The peak with moderate strength at $598 \mathrm{~cm}^{-1}$ is attributed to the (Cr-O) vibration, which proves that Cr-MIL-101 was actually synthesized. The difference in spectra was clearly observed after modification with sulfamic acid as shown in Fig. 3b-d. Two weak bands were observed at 3137 and $3439 \mathrm{~cm}^{-1}$, which are related to the symmetrical and asymmetrical stretching vibrations of amine groups. ${ }^{64}$ On the other hand, new bands appeared at 1185 and $1297 \mathrm{~cm}^{-1}$, which are related to the $(\mathrm{O}=\mathrm{S}=\mathrm{O})$ symmetric and asymmetric stretching modes, respectively; the increasingly weak band due to increasing sulfamic acid content appeared at $1053 \mathrm{~cm}^{-1}$ and was assigned to (S-O) stretching vibration. ${ }^{65}$ The existence of 


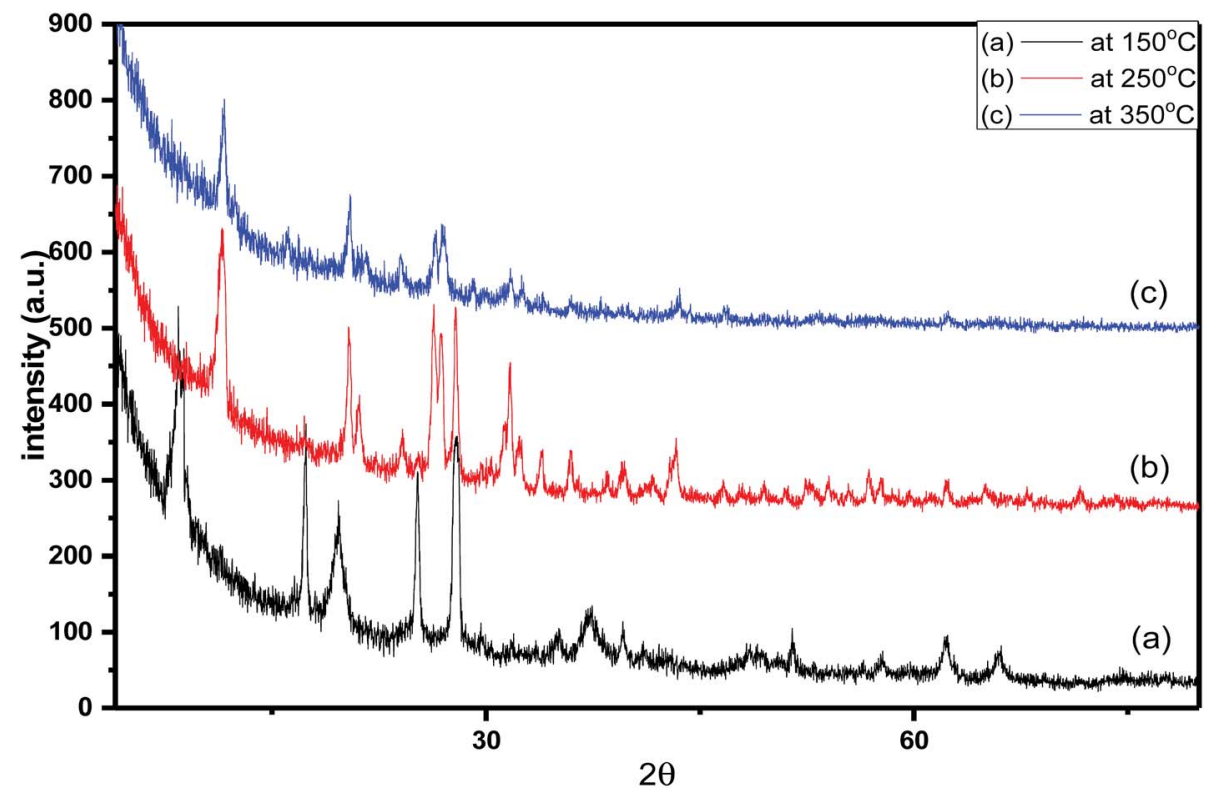

Fig. 2 X-ray diffraction pattern of $55 \%$ sulfamic acid loaded on MIL-101 at (a) $150{ }^{\circ} \mathrm{C}$, (b) $250^{\circ} \mathrm{C}$ and (c) $350{ }^{\circ} \mathrm{C}$.

a new vibrational peak at $665 \mathrm{~cm}^{-1}$ was related to $\mathrm{NH}_{2}$ and $\mathrm{N}-\mathrm{H}$ wagging for sulfamic acid. ${ }^{62}$ The FTIR spectra of modified MIL$101(\mathrm{Cr})$ confirmed the presence of sulfamic acid loaded on $\mathrm{Cr}$ MIL-101.

Fig. 4 shows the effect of the calcination temperature of $55 \%$ sulfamic acid on the IR spectra of MIL-101 (Cr). When the calcination temperature increased from $150{ }^{\circ} \mathrm{C}$ to $350{ }^{\circ} \mathrm{C}$, the intensity of the $1185 \mathrm{~cm}^{-1}$ band decreased sharply and the other three peaks at 665, 1053 and $1297 \mathrm{~cm}^{-1}$ nearly disappeared at $350{ }^{\circ} \mathrm{C}$ due to the decomposition of sulfamic acid.

\subsection{TEM and SEM images}

The particle size and surface morphology of pure and modified MIL-101 samples were characterized by using SEM and TEM and the results are shown in Fig. 5 and 6. The typical TEM and SEM images of pure and modified MIL-101 samples showed that the crystals had a regular octahedral structure with smooth surface and average diameters of $300-500 \mathrm{~nm} .{ }^{66}$ As also depicted in Fig. 6, it is clear that there was no aggregation of sulfamic acid crystals in TEM images up to $55 \mathrm{wt} \%$ of sulfamic acid. However, some aggregation was observed on the MIL-101 surface in the case of 85 wt\% SA/MIL-101, which could be due to formation of aggregates of sulfamic acid crystals.

\subsection{BET measurements}

The resulting pore modifications were observable in the $\mathrm{N}_{2}$ adsorption isotherms of pristine MIL-101 (Cr) and sulfamic acid loaded on MIL-101 (Cr). The $\mathrm{N}_{2}$ adsorption isotherms and pore-

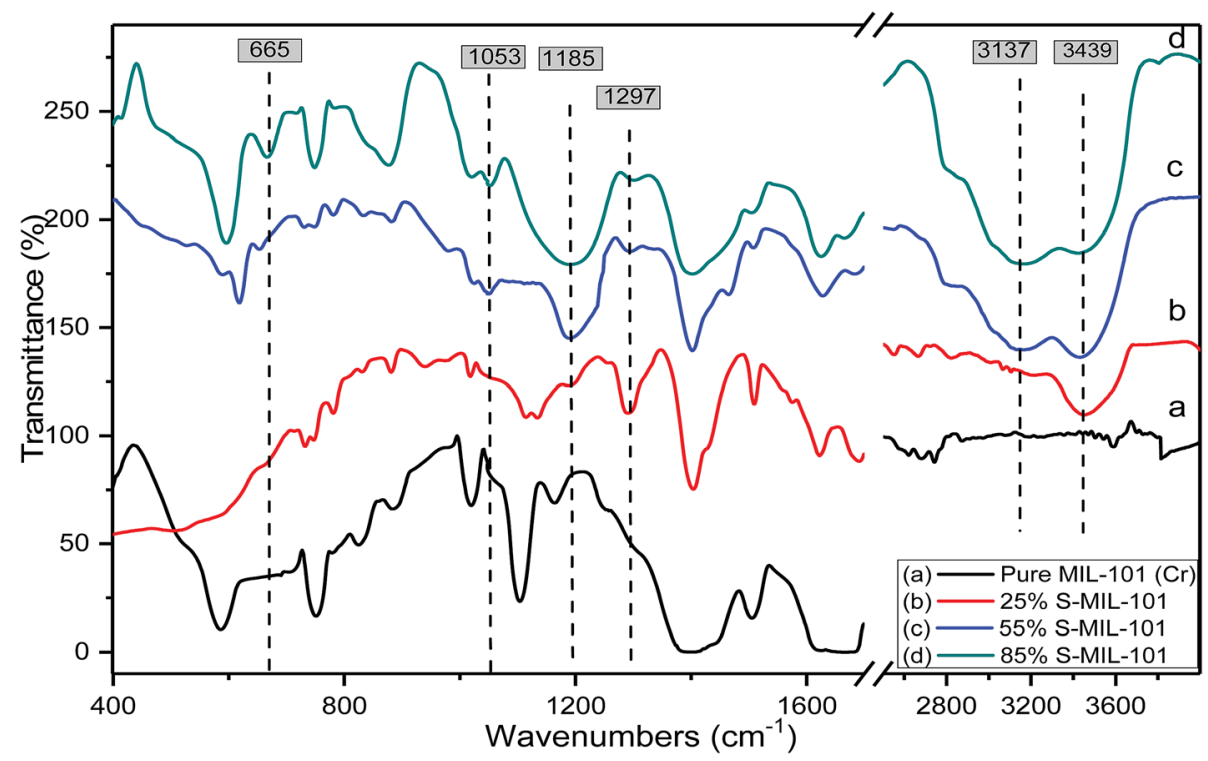

Fig. 3 FTIR spectra of (a) Cr-MIL-101; (b) 25\% SA@MIL-101; (c) 55\% SA@MIL-101 and (d) 85\% SA@MIL-101. 


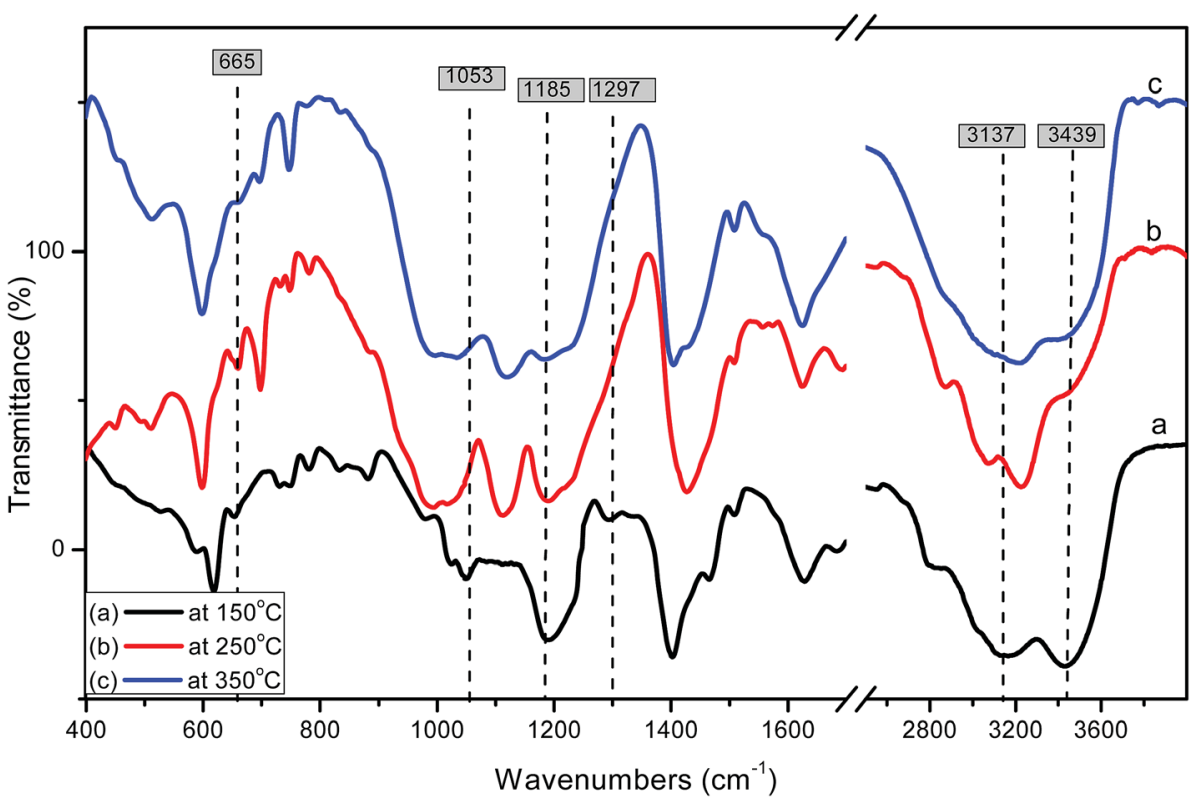

Fig. 4 FTIR spectra of $55 \%$ sulfamic acid loaded on MIL-101 at (a) $150{ }^{\circ} \mathrm{C}$; (b) $250{ }^{\circ} \mathrm{C}$ and (c) $350{ }^{\circ} \mathrm{C}$.

size distribution curves are shown in Fig. 7. The BET surface area and pore volume of the pristine MIL-101 $(\mathrm{Cr})$ are $2989 \mathrm{~m}^{2}$ $\mathrm{g}^{-1}$ and $1.645 \mathrm{~cm}^{3} \mathrm{~g}^{-1}$, respectively, which are in agreement with earlier reports. ${ }^{67}$ After modification with sulfamic acid, the SA/MIL-101 samples exhibited a significant decrease in the $\mathrm{N}_{2}$ adsorption amounts and the corresponding BET surface areas were decreased to $944 \mathrm{~m}^{2} \mathrm{~g}^{-1}$ with the increase in the sulfamic acid content. On the other hand, the pore size and the pore volume gradually decreased with the increase in the sulfamic acid contents as shown in Table 1 . This could be due to the pore blockage produced by the deposition of sulfamic acid crystals inside the pores. As can be seen from the pore size distribution curves (Fig. 7Y), the incorporation of sulfamic acid resulted in a decrease in the pore volume and there was a slight shift to a smaller pore diameter compared to Cr-MIL-101.

\subsection{Surface acidity studies}

3.5.1 Non-aqueous titration. The total acidity of pure and modified MIL-101 materials was described using non-aqueous titration with $n$-butyl amine $\left(\mathrm{p} K_{\mathrm{a}}=10.73\right)$. By using this
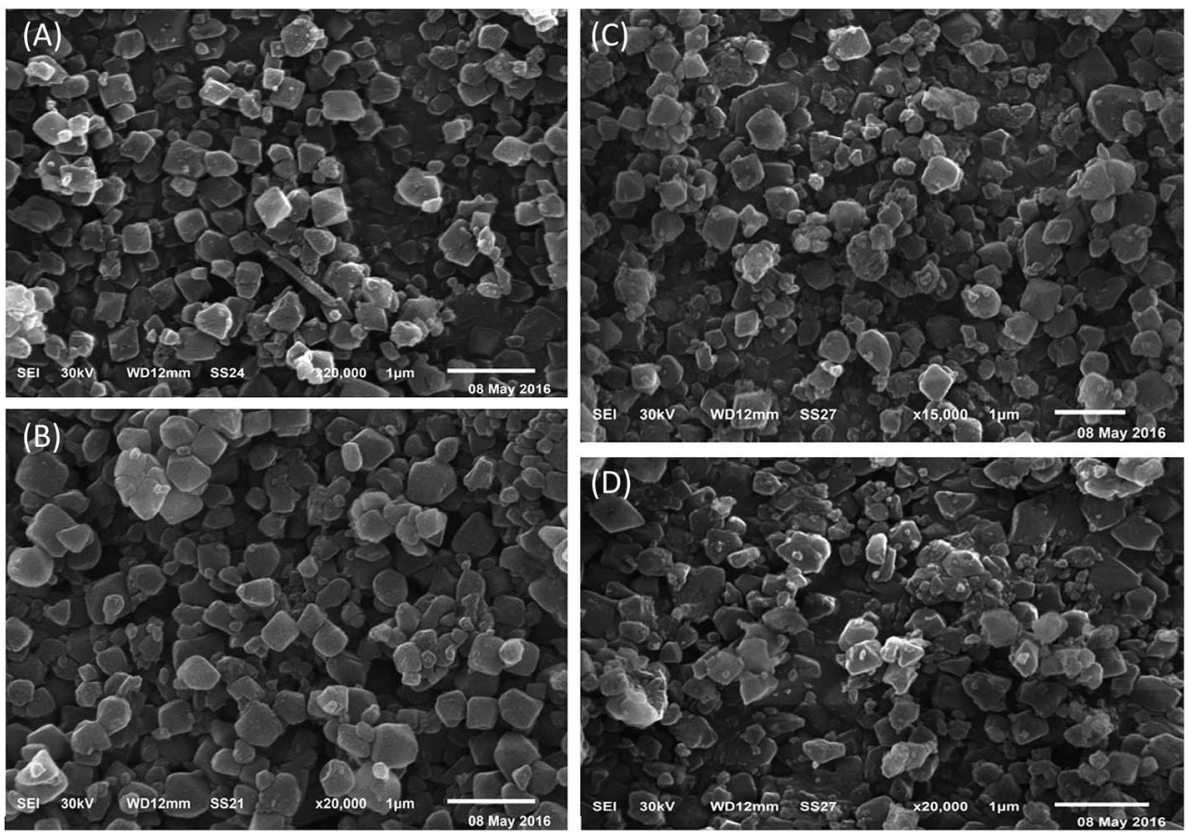

Fig. 5 SEM images of (A) pure MIL-101, (B) 25 wt\%, (C) 55 wt\%, (D) 85 wt\% sulfamic acid/MIL-101. 

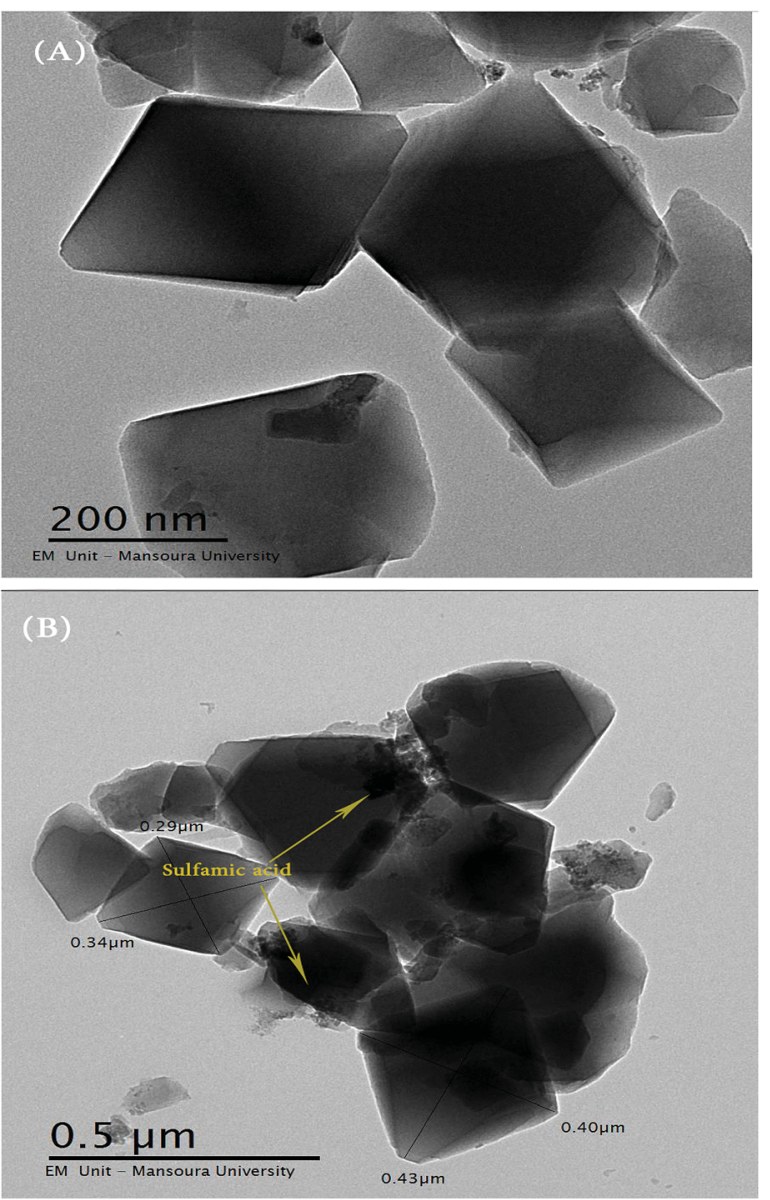
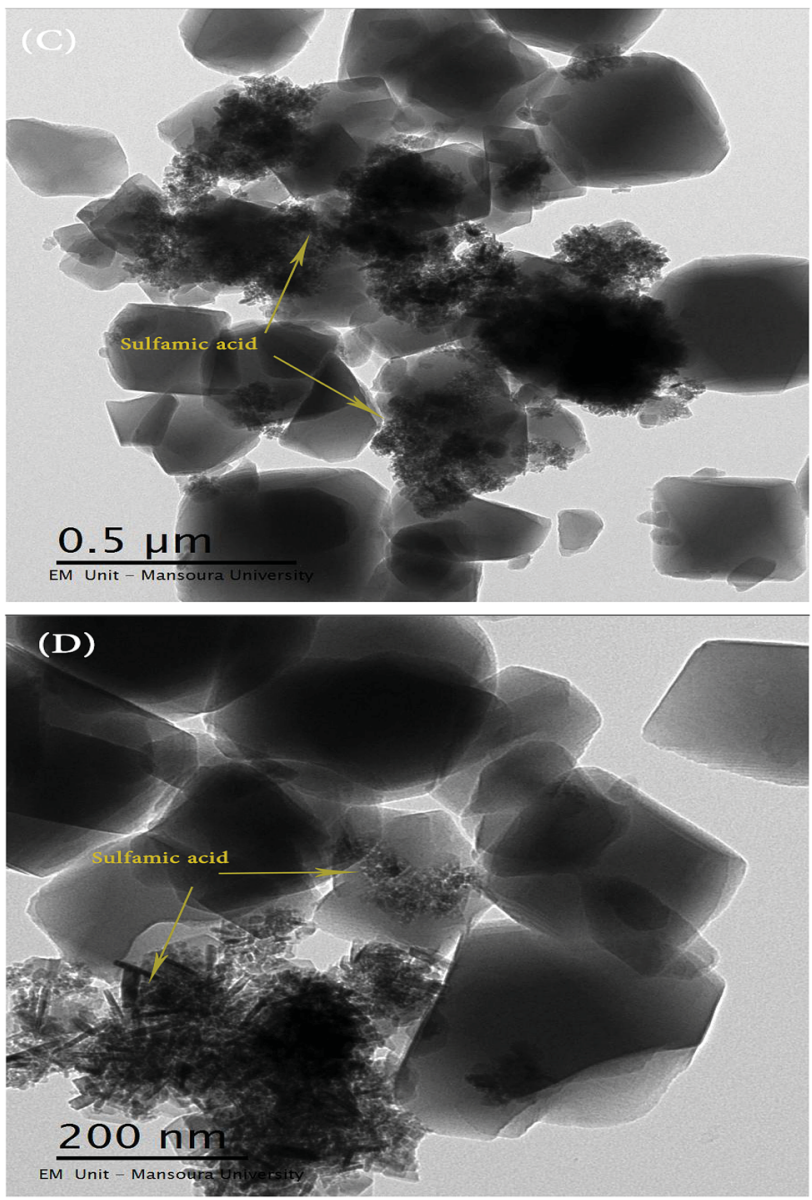

Fig. 6 TEM images of (A) pure MIL-101, (B) 25 wt\%, (C) 55 wt\%, (D) 85 wt\% sulfamic acid/MIL-101.

technique, it is possible to investigate the surface acidity characteristics of acidic strength and total number of acid sites present in the solids. From the potentiometric titration curves, the point where the plateau is reached (mmole amine per $\mathrm{g}$ ) is equivalent to the total number of acid sites of the catalysts, calculated from the following relation: ${ }^{68}$

$$
\begin{aligned}
& \text { Total number of acid sites } / \mathrm{g} \\
& \quad=\frac{\text { steady point of plateau } \times\left(\text { equiv. } \mathrm{g}^{-1}\right) \times N_{\mathrm{A}}}{100}
\end{aligned}
$$

where $N_{\mathrm{A}}$ is Avogadro's number.

On the other hand, the acid strength of the catalyst sites may be categorized according to the following scale: $E_{\mathrm{i}}>100 \mathrm{mv}$ (very strong sites), $0<E_{\mathrm{i}}<100 \mathrm{mv}$ (strong sites), $-100<E_{\mathrm{i}}<0 \mathrm{mv}$ (weak sites) and $E_{\mathrm{i}}<-100 \mathrm{mv}$ (very weak sites). ${ }^{69}$ Fig. 8 shows that the addition of sulfamic acid increases the acidity strength of Cr-MIL-101 and generated strong acid sites on the surfaces. Pure Cr-MIL-101 showed a maximum acidity of $E_{\mathrm{i}}=148 \mathrm{mv}$; however, the incorporation of sulfamic acid in MIL-101 was accompanied by a progressive increase in acidic strength up to $55 \%$ SA/MIL-101, where $E_{\mathrm{i}}=533 \mathrm{mv}$ as shown in Table 2, then a decrease. Also, the total number of acid sites/gram were varied in the same trend as the total surface acidity as shown in Fig. 9.
These results indicate that the distribution of sulfamic acid loaded on the Cr-MIL-101 surface was the maximum and was responsible for higher acidity. The super acidic property is related to the double bond nature of $(\mathrm{S}=\mathrm{O})$ in the complex formed by interaction of MIL-101 with sulfamic acid. In other words, the acid strength of the SA/MIL-101 catalysts became stronger with the inductive effect of $(\mathrm{S}=\mathrm{O}) \mathrm{.}^{70}$

Fig. 10 and 11 show the gradual loss of surface acidity and total number of acid sites at higher calcination temperatures for $55 \%$ SA/MIL-101, which may be attributed to the partial evolution of $\mathrm{SO}_{3}$ that decomposed from sulfamic acid bound to the Cr-MIL-101 surface. This was further confirmed by FTIR spectra and XRD.

3.5.2 Pyridine adsorption. The adsorption of pyridine is an efficient method used to investigate Brønsted acid sites and Lewis acid sites. FTIR spectra of the chemisorbed pyridine of catalysts with different amounts of sulfamic acid and different calcination temperatures are shown in Fig. 12 and 13, respectively. The spectra of all investigated samples contain strong peaks with a maximum at $1438 \mathrm{~cm}^{-1}$ and $1488 \mathrm{~cm}^{-1}$. The band at about $1438 \mathrm{~cm}^{-1}$ is related to coordinated pyridine (Lewis acid sites) and the band at $1488 \mathrm{~cm}^{-1}$ is related to pyridine adsorption at Brønsted acid sites. The percentage of Bronsted 

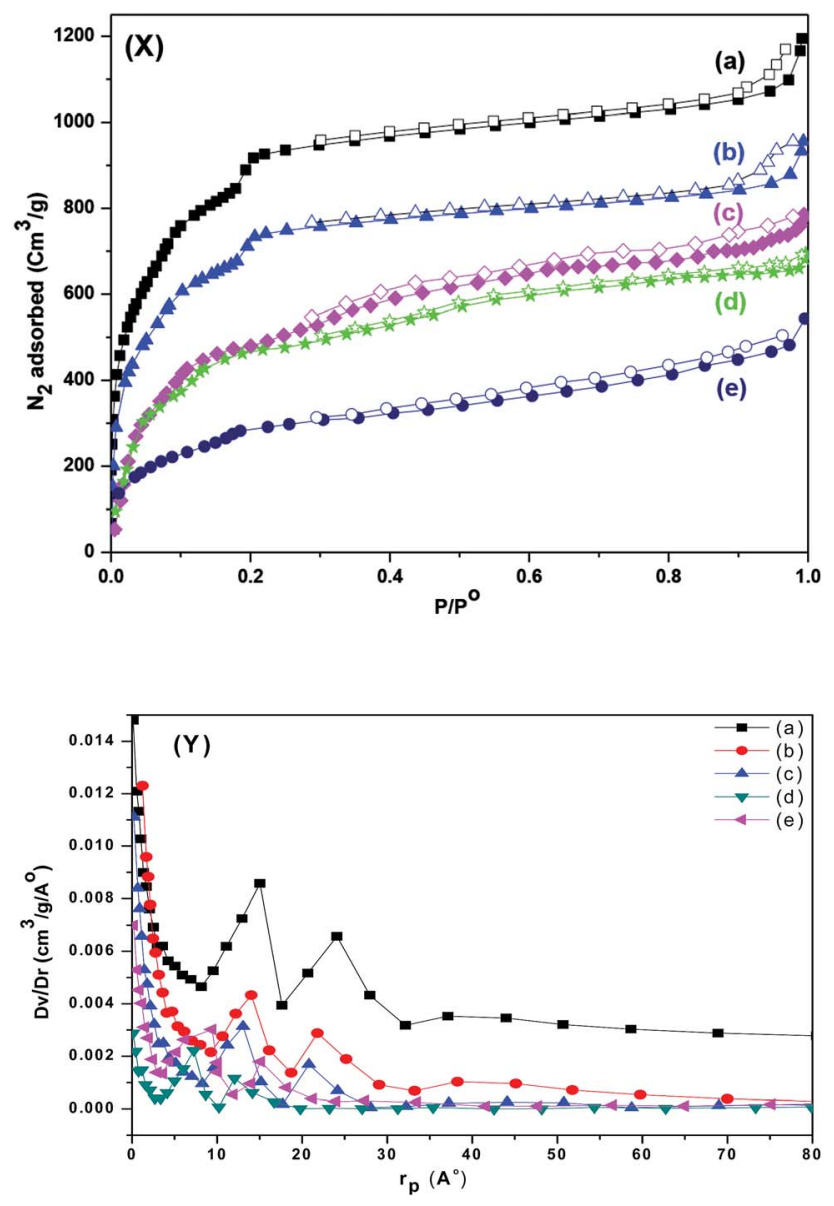

Fig. $7(X) N_{2}$ adsorption-desorption isotherm at $77 \mathrm{~K} ;(\mathrm{Y})$ the corresponding pore size distribution of (a) Cr-MIL-101; (b) 15 wt\% SA/MIL101; (c) 25 wt\% SA/MIL-101, (d) 55 wt\% SA/MIL-101 and (e) 85 wt\% SA/ MIL-101.

Table 1 Texture properties of modified and unmodified Cr-MIL-101

\begin{tabular}{lll}
\hline Sample name & $S_{\text {BET }}\left(\mathrm{m}^{2} \mathrm{~g}^{-1}\right)$ & $V_{\text {pore }}\left(\mathrm{cm}^{3} \mathrm{~g}^{-1}\right)$ \\
\hline Pure Cr-MIL-101 at $150{ }^{\circ} \mathrm{C}$ & 2989 & 1.645 \\
$15 \%$ SA-MIL-101 at $150{ }^{\circ} \mathrm{C}$ & 2391 & 1.276 \\
$25 \%$ SA-MIL-101 at $150{ }^{\circ} \mathrm{C}$ & 1730 & 1.012 \\
$55 \%$ SA-MIL-101 at $150{ }^{\circ} \mathrm{C}$ & 1387 & 0.877 \\
$85 \%$ SA-MIL-101 at $150{ }^{\circ} \mathrm{C}$ & 944 & 0.639
\end{tabular}

and Lewis acid sites were calculated from the following relations: ${ }^{71}$

$$
\begin{gathered}
\% \text { Bronsted }=\frac{A_{\mathrm{B}}}{\left(A_{\mathrm{B}}+A_{\mathrm{L}}\right)} \times 100 \\
\% \text { Lewis }=\frac{A_{\mathrm{L}}}{\left(A_{\mathrm{B}}+A_{\mathrm{L}}\right)} \times 100
\end{gathered}
$$

where $A_{\mathrm{B}}$ is the integrated area of the peak at $1488 \mathrm{~cm}^{-1}$, attributed to the pyridinium cation adsorbed on the Bronsted acid site, and $A_{\mathrm{L}}$ is the intensity at $1438 \mathrm{~cm}^{-1}$ of the pyridine molecule coordinated to the Lewis acid site.

From these data, pure Cr-MIL-101 contained only Lewis acid sites, observed at $1438 \mathrm{~cm}^{-1}$, while both Lewis and Brønsted acid sites were observed in all the samples with various ratios depending on the sulfamic acid content. The ratios of Brønsted/ Lewis $(\mathrm{B} / \mathrm{L})$ sites that are shown in Table 2 were calculated from the ratio of the peak area at $1488 \mathrm{~cm}^{-1}$ and $1438 \mathrm{~cm}^{-1}$, respectively. Brønsted/Lewis acid (B/L) ratios increased with the increase in sulfamic acid content up to 55\% SA/MIL-101, then decreased again. The $\mathrm{B} / \mathrm{L}$ ratio decreased with an increase in calcination temperature and this expected decrease may be due to the evolution of $\mathrm{SO}_{3}$ from sulfamic acid bound to Cr-MIL-101 surface. ${ }^{47}$

\subsection{Catalytic studies}

3.6.1 Synthesis of 14-phenyl-14H-dibenzo [a,j] xanthene. Condensation between benzaldehyde and $\beta$-naphthol was carried out with $50 \mathrm{mg}$ of supported catalyst without using any solvents at $120-125{ }^{\circ} \mathrm{C}$ for the synthesis of the desired xanthene. A background reaction was conducted in the absence of supported catalysts and no product was obtained. In this reaction, we have efficaciously used solid acid catalysts as substitutions for the classical methods of preparation of the desired xanthene, which was characterized by its melting point $(\mathrm{mp}=$ $185^{\circ} \mathrm{C}$ ) and FT-IR spectroscopy. The percentage yields of the products (\%) were calculated as the quantity of experimental xanthene $(\mathrm{g})$ divided by the quantity of theoretical xanthene $(\mathrm{g})$ $\times 100$.

3.6.1.1 The effects of reaction molar ratio and reaction time. The molar ratio of the reaction during the synthesis of the desired xanthenes was studied by using 55\% SA-MIL-101 as shown in Fig. 14. After completion of the reaction (monitored by TLC), it was observed that the percentage yield of the desired xanthene increased from $48.2 \%$ to $93.7 \%$ with the increase of the molar ratio of benzaldehyde : $\beta$-naphthol from $1: 1$ to $1: 2$. A further increase to $1: 3$ and $1: 4$ was accompanied by a significant loss in the product yield of the desired xanthenes to $77.4 \%$ and $56.8 \%$, respectively. The reduction in catalytic activity could be elucidated based on the known fact that the increase in the concentration of $\beta$-naphthol inhibits the reaction by blocking the active sites on the catalyst surface. ${ }^{72}$

The reaction time for the synthesis of xanthene over $55 \%$ SAMIL-101 was monitored by TLC, which indicated that all the reactants disappeared after 90 minutes and just one product was formed. The reaction was studied using $0.05 \mathrm{~g}$ of supported catalysts under the following reaction conditions: temperature $=125^{\circ} \mathrm{C}$; time $=1.5 \mathrm{~h}$ and molar ratio $=1: 2$ (benzaldehyde $: \beta$ naphthol).

3.6.1.2 Effects of sulfamic acid content and calcination temperature. The catalytic activities of unmodified and sulfamic acid-modified Cr-MIL-101, calcined at $150{ }^{\circ} \mathrm{C}$ for $2 \mathrm{~h}$ in the synthesis of the desired xanthene were studied at $125{ }^{\circ} \mathrm{C}$ using the reactant molar ratio of 1 : 2 (benzaldehyde : $\beta$-naphthol) for 90 min. Pure Cr-MIL-101 showed a slightly lower activity because the active sites of MIL-101 have a very weak acidic 


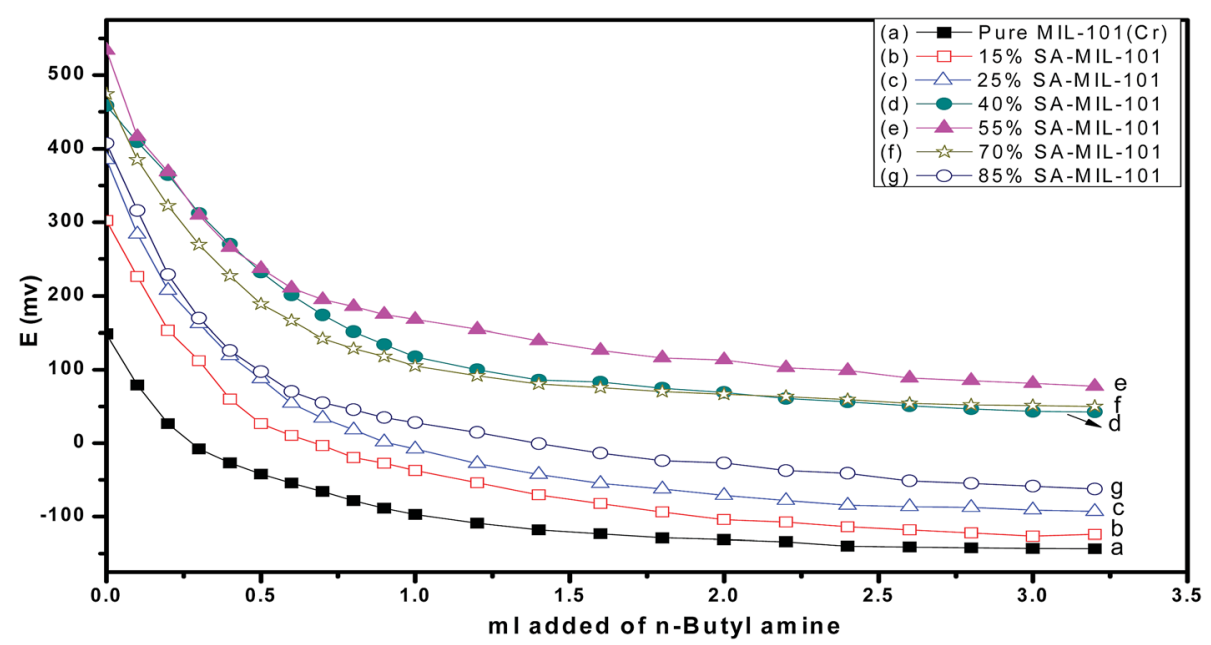

Fig. 8 Potentiometric titration curves of catalysts calcined at $150^{\circ} \mathrm{C}$.

nature. However, MIL-101 modified with various wt\% of sulfamic acid showed that the percentage yield of the desired xanthene increased with an increase in the sulfamic acid content up to 55 wt\% SA-MIL-101, which showed the highest activity with $94 \%$ of desired xanthene. There was a subsequent decrease with the further increase in sulfamic acid content, which may be due to the decrease in the surface acidity of the supported catalysts. It was also noticed that the reaction yield increased with the increase in Brønsted to Lewis acid sites ratio as shown in Table 2. These results indicate that the formation of the desired xanthenes depends on the $\mathrm{B} / \mathrm{L}$ ratio.

The effect of the calcination temperatures (150, 250 and 350 ${ }^{\circ} \mathrm{C}$ ) on the yield of desired xanthene over the 55\% SA-MIL-101 catalyst is also shown in Table 2. Examination of the table shows that with the increase in the calcination temperature, the percent yield decreases because of the reduction in the catalyst acidity and Brønsted/Lewis acid sites ratio as a result of the decomposition of sulfamic acid and evolution of $\mathrm{SO}_{x}$ moieties.

The results obtained in this work using sulfamic acid loaded on MIL-101 were compared with other reported results in literature; i.e., with nano- $\mathrm{ZnO},{ }^{73}$ sulfamic acid, ${ }^{74}$ tungstate sulfuric acid $^{75}$ and $\mathrm{L}$-proline, $\mathrm{DCE}^{76}$ in the synthesis of the desired xanthene. From these results, sulfamic acid supported on MIL-101 acted as efficacious catalyst with regard to the obtained product, yield and the reaction times.

3.6.1.3 Reusability of the catalyst. The reusability of SA-MIL101 catalysts was examined; a typical recycling study on the sample with 55 wt\% SA-MIL-101 was performed by separating the catalyst from the reaction, washing with ethanol and drying at $120^{\circ} \mathrm{C}$. After that, the stability of the catalyst was investigated via studying the stability of the characteristic IR bands of the sulfate groups before and after using the catalyst 4 times. There were small changes in the peak intensity, which were related to the $\mathrm{SO}_{3} \mathrm{H}$ group as shown in Fig. 16. The catalyst showed a small but significant loss in activity after four cycles as shown in Fig. 15 for the preparation of the desired xanthene; this is because xanthene synthesis depends on both Bronsted acid sites $\left(\mathrm{SO}_{3} \mathrm{H}\right)$ and Lewis acid sites.

3.6.2 7-Hydroxy-4-methyl coumarin synthesis. 7-Hydroxy-4methylcoumarin was synthesized via the Pechmann condensation reaction using ethyl acetoacetate and resorcinol.

3.6.2.1 The effect of the molar ratio. The effect of the molar ratio on the formation of the desired coumarin was investigated using $100 \mathrm{mg}$ of 55\% SA-MIL-101, as shown in Fig. 14. The yield of the desired coumarin increased from 48.2 to $72.8 \%$ with the increase in the molar ratio of resorcinol : ethyl acetoacetate

Table 2 Surface acidities of the prepared catalysts determined by potentiometric titration with $n$-butylamine in acetonitrile and pyridine adsorption with the percentage yield of 14-phenyl-14H-dibenzo [a,j] xanthene and 7-hydroxy-4-methyl coumarin

\begin{tabular}{|c|c|c|c|c|c|}
\hline Pure Cr-MIL-101 at $150{ }^{\circ} \mathrm{C}$ & +148.2 & 2.031 & - & 38.2 & 0 \\
\hline $25 \%$ SA-MIL- 101 at $150{ }^{\circ} \mathrm{C}$ & +385.4 & 3.612 & 2.43 & 67.1 & 25.4 \\
\hline $40 \%$ SA-MIL- 101 at $150{ }^{\circ} \mathrm{C}$ & +458.4 & 3.987 & 2.93 & 79.8 & 39.5 \\
\hline $55 \%$ SA-MIL- 101 at $150{ }^{\circ} \mathrm{C}$ & +533.8 & 4.425 & 4.86 & 93.7 & 72.8 \\
\hline $55 \%$ SA-MIL- 101 at $250{ }^{\circ} \mathrm{C}$ & +364.0 & 3.533 & 2.31 & 61.1 & 51.1 \\
\hline $55 \%$ SA-MIL- 101 at $350{ }^{\circ} \mathrm{C}$ & +308.0 & 3.441 & 2.11 & 47.5 & 38.2 \\
\hline
\end{tabular}




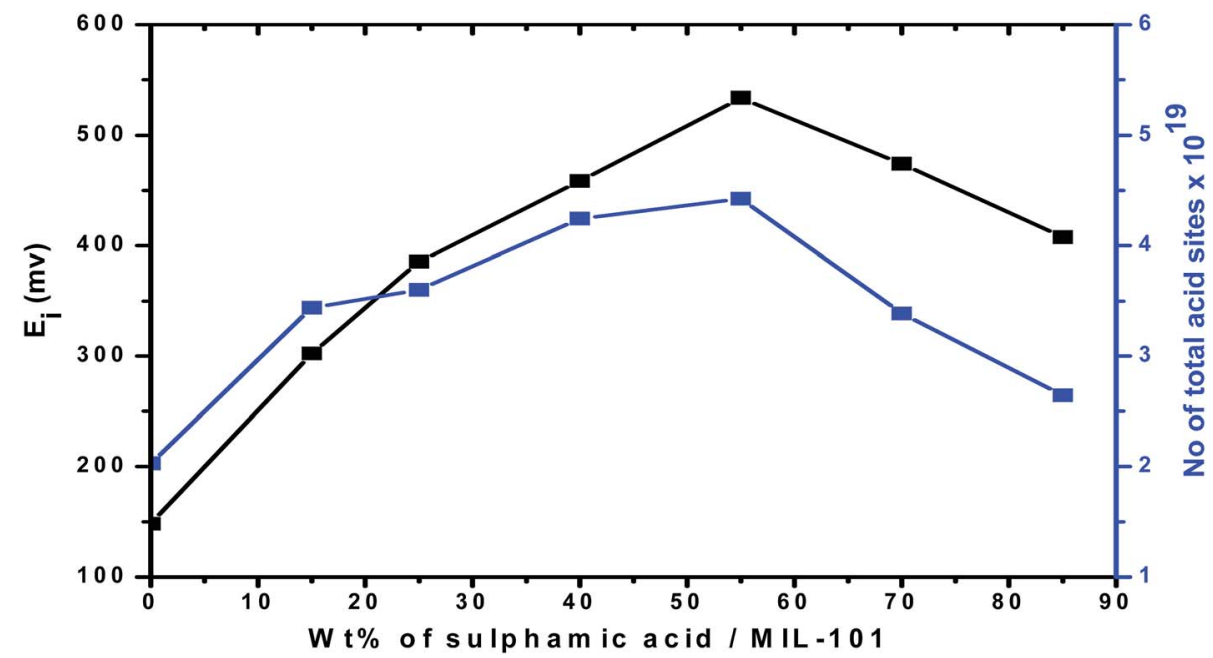

Fig. 9 Total number of acid sites and initial potential vs. weight percent of sulfamic acid over MIL-101.

from $1: 1$ to $1: 2$. A further increase to $1: 3$ was accompanied by a significant decrease in the percentage yield of the desired coumarin to $54.7 \%$. The decrease in the catalytic activity with the further increase in the ethyl acetoacetate molar ratio was due to the saturation of the catalyst surface with the ethyl acetoacetate, which blocked the acid adsorption centers. The efficiency of the catalyst was therefore reduced due to the competitive adsorption of the ethyl acetoacetate on the acid sites with resorcinol. ${ }^{59}$

3.6.2.2 The effect of sulfamic acid content and calcination temperature. The synthetic reaction was conducted over pure and modified MIL-101 using sulfamic acid at $120{ }^{\circ} \mathrm{C}$ for two hours, with the molar ratio of the reactants being $1: 2$ (resorcinol : ethyl acetoacetate). Pure MIL-101 did not have considerable catalytic activity in the reaction, which may be attributed to the weakly acidic active sites on the MIL-101 framework. On the other hand, MIL-101 modified with various amounts of sulfamic acid showed higher activity. Table 2 shows that the percentage yield of the desired coumarin gradually increased with increasing the amount of sulfamic acid loaded on Cr-MIL101 until the maximum yield was reached (72.8\%) at $55 \mathrm{wt} \%$ SAMIL-101, and then decreased. The decrease in the catalyst activity may be due to the aggregation of sulfamic acid crystals, as shown in the TEM images, which resulted in the decrease in the surface acidity of the samples and the $\mathrm{B} / \mathrm{L}$ ratio. Table 2 shows that the sharp decrease in both the acidity and catalytic activity with further increase in the calcination temperature may be attributed to the decomposition of sulfamic acid and the evolution of $\mathrm{SO}_{x}$ moieties.

A comparison was made of the results obtained in this work using sulfamic acid loaded on MIL-101 with those achieved using polyaniline-sulfate, ${ }^{77}$ aniline-sulfosalicylate, ${ }^{77}$ amberlyst15 (ref. 78) and heteropoly acid/MIL-101 catalysts. ${ }^{68}$ The results indicate that $\mathrm{SA} / \mathrm{MIL}-101$ acts as an effective catalyst in the synthesis of the desired coumarin with respect to yields and products.

3.6.2.3 The reusability of the catalyst. Upon completion of the reaction, the reusability of the $55 \%$ SA-MIL-101 sample was

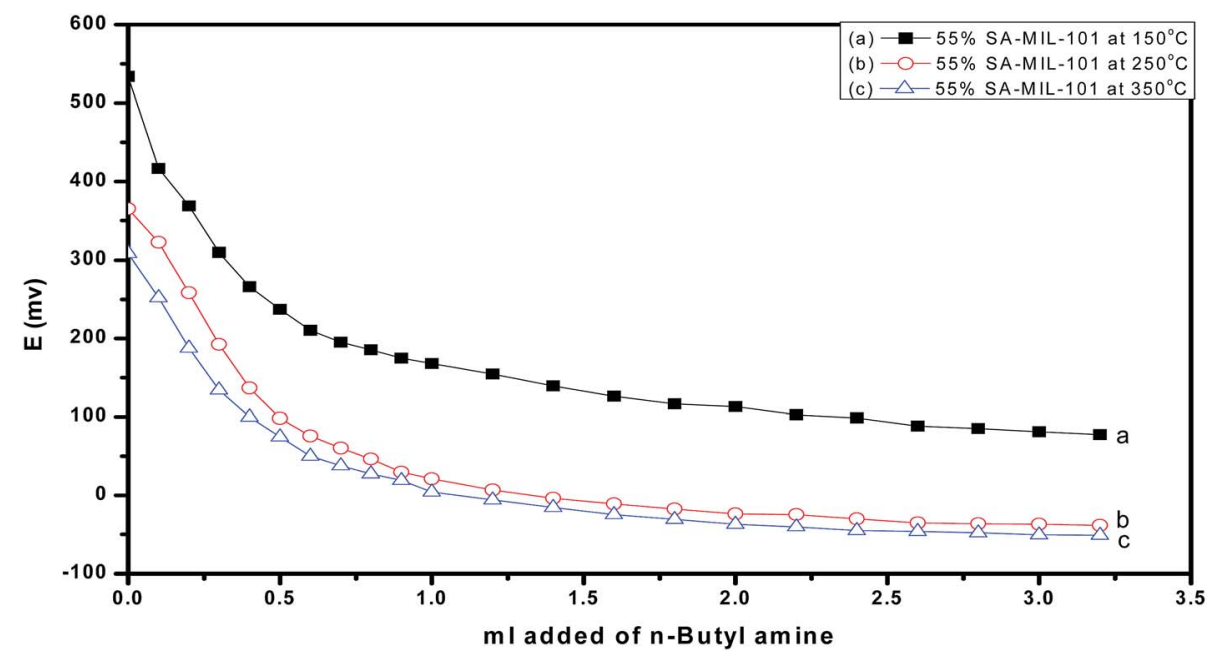

Fig. 10 Potentiometric titration curves of 55\% SA-MIL-101 calcined at different temperatures. 


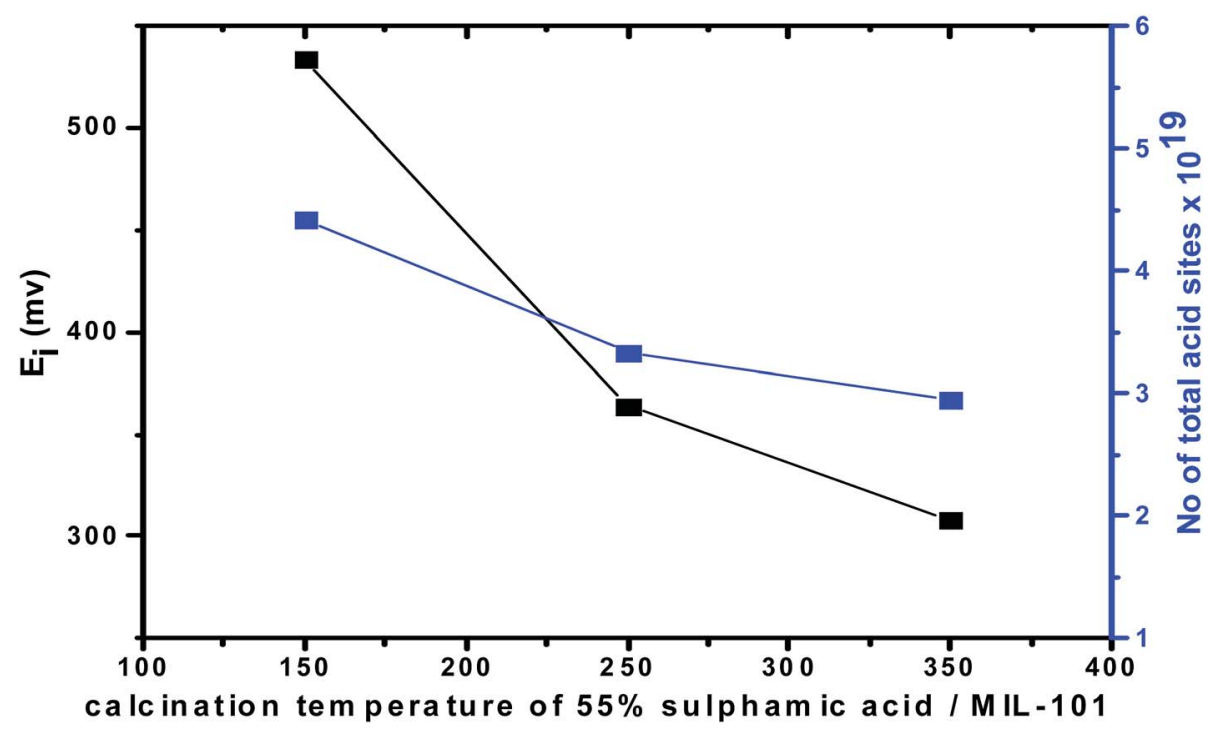

Fig. 11 Total number of acid sites and initial potential vs. calcination temperature of 55\% SA/MIL-101.

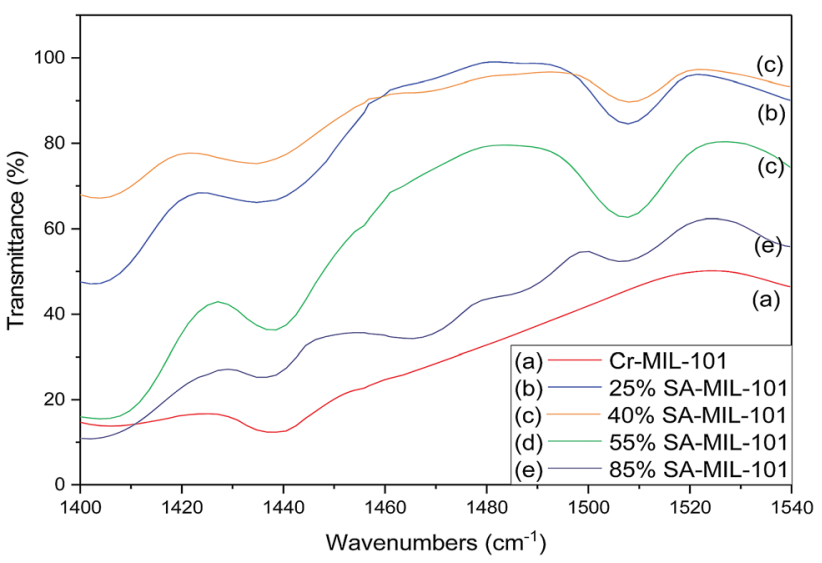

Fig. 12 FT-IR spectra of chemisorbed pyridine (showing both Lewis (L) and Brønsted (B) acid sites) on (a) Cr-MIL-101, (b) 25\% SA-MIL-101, (c) 40\% SA-MIL-101, (d) 55\% SA-MIL-101 and (e) 85\% SA-MIL-101 calcined at $150{ }^{\circ} \mathrm{C}$.

investigated and the catalyst was found to be re-usable for at least three times as shown in Fig. 15, where it can be seen that the catalytic activity decreased from $72.9 \%$ to $48.4 \%$ after three uses. This decrease may be due to the removal of some Brønsted acid sites $\left(\mathrm{SO}_{3} \mathrm{H}\right)$ as evidenced in the leaching test shown in Fig. 16, since the synthesis of coumarin basically depends on Brønsted acid sites. ${ }^{79}$

\subsection{Adsorption of methyl orange}

3.7.1 Effect of $\mathbf{p H}$. One of the most vital parameters for the whole adsorption process is adjusting the $\mathrm{pH}$ of the dye solution, which influences not only the charge on the active sites of the adsorbent but also the ionization degree of the MO solution during the adsorption process. ${ }^{80}$ Therefore, in this work, the $\mathrm{pH}$ was studied in the range of 2.0-12.0 using the initial dye concentration of 100 ppm as shown in Fig. 17. This figure shows

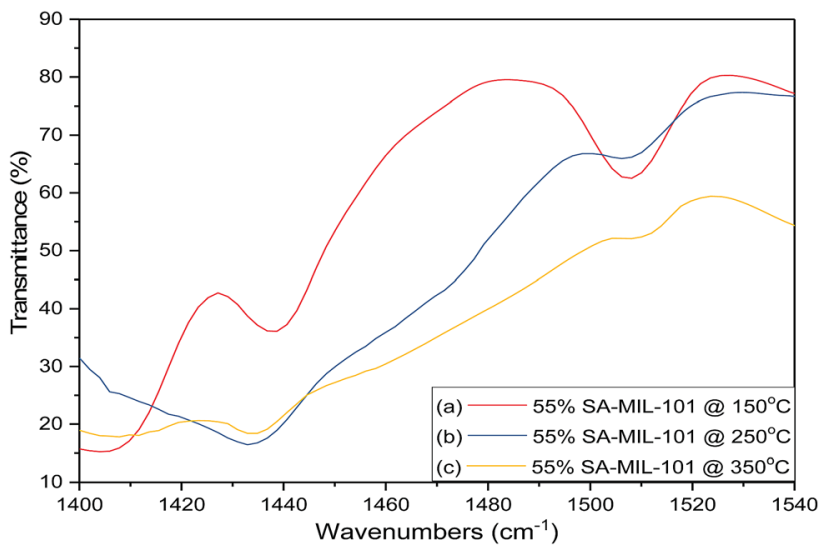

Fig. 13 FT-IR spectra of chemisorbed pyridine (showing both Lewis (L) and Brønsted (B) acid sites) on 55\% SA-MIL-101 calcined at (a) $150{ }^{\circ} \mathrm{C}$; (b) $250^{\circ} \mathrm{C}$ and (C) $350^{\circ} \mathrm{C}$

that the adsorbed amount of MO at equilibrium $\left(q_{\mathrm{e}}\right)$ decreased from 96.9 to $7.5 \mathrm{mg} \mathrm{g}^{-1}$ as the $\mathrm{pH}$ changed from 2 to 12 . The optimum $\mathrm{pH}$ was frequently reported to be at about $\mathrm{pH} 2.0$ when 55\% SA-MIL-101 was used as the adsorbent. At this $\mathrm{pH}$, a high electrostatic attraction exists between the anionic dye (MO) and the positively charged surface of the adsorbent (containing amine groups), which may be attributed to the protonation of the amines in sulfamic acid before adsorption. ${ }^{\mathbf{8 1}}$ Methyl orange molecules exist as negatively charged species until $\mathrm{pH}$ 3.46 , after which they exist as neutral, and then in high $\mathrm{pH}$ conditions they exist as slightly positively charged species. However, the adsorption weakened with the increase in the $\mathrm{pH}$ of the MO solution. This decrease may be due to the competition between $\mathrm{MO}$ anions and the abundant $\mathrm{OH}^{-}$ions in basic solution. $^{82}$

The adsorption mechanism may be as follows:

Firstly, the methyl orange dye $\left(\mathrm{R}-\mathrm{SO}_{3} \mathrm{Na}\right)$ decomposes into anions when dissolved in an aqueous solution. 

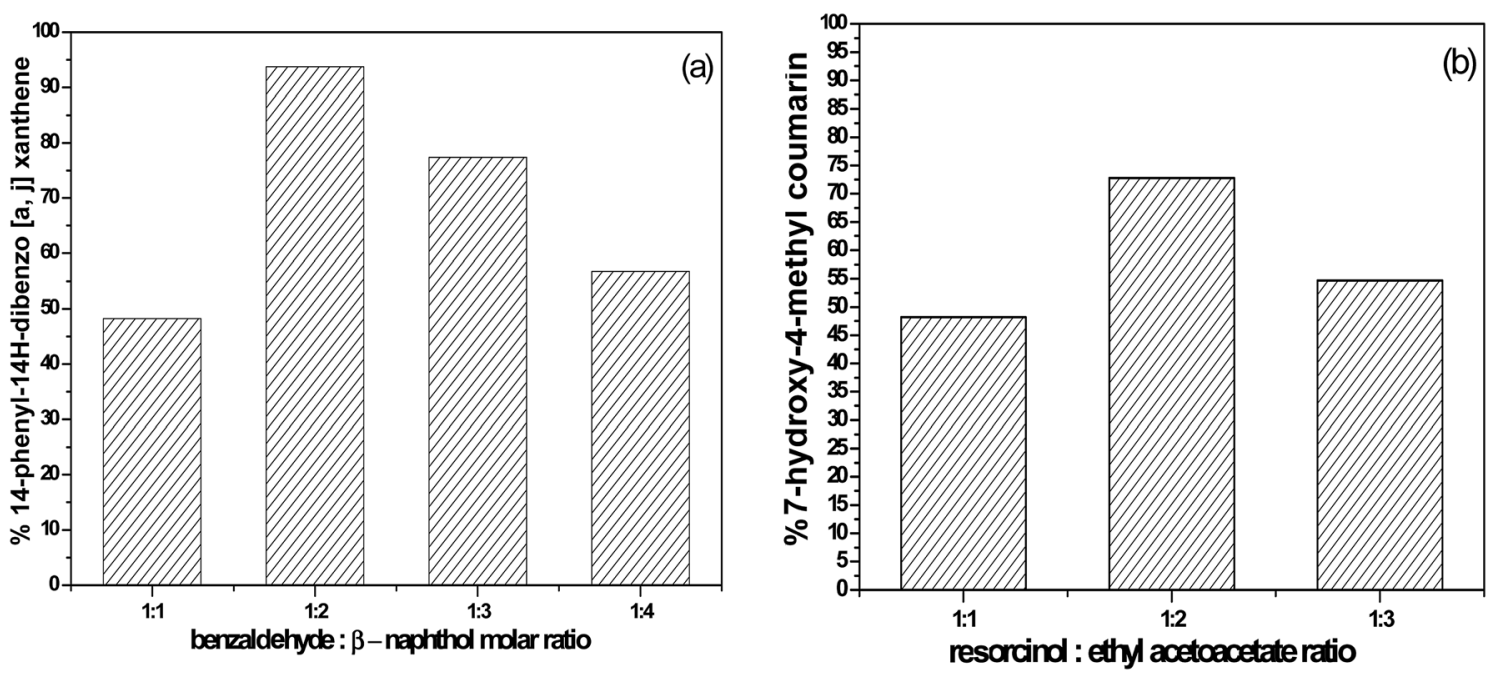

Fig. 14 The effect of the molar ratio of (a) benzaldehyde : $\beta$-naphthol and (b) resorcinol : ethyl acetoacetate on the catalytic activity over $55 \%$ SA-MIL-101.

$$
\mathrm{R}-\mathrm{SO}_{3} \mathrm{Na}+\mathrm{H}_{2} \mathrm{O} \rightarrow \mathrm{R}-\mathrm{SO}_{3}{ }^{-}+\mathrm{Na}^{+}
$$

Secondly, the adsorption process is achieved due to electrostatic attractions between the MO anions and the adsorbent surface. ${ }^{83}$

$$
\mathrm{RNH}_{3}{ }^{+}+\mathrm{RSO}_{3}{ }^{-} \rightarrow \mathrm{RNH}_{3}{ }^{+} \mathrm{O}_{3} \mathrm{SR}
$$

Thus, pH close to 2 was selected as optimal for the following adsorption experiments.

3.7.2 Effect of contact time and adsorption kinetics studies. Contact time is one of the most vital variables in the adsorption process. Fig. 18 shows the evolution of the amount of adsorbed MO at any time $\left(q_{t}\right)$ with contact time $(t)$ over modified and unmodified Cr-MIL-101 using initial dye concentration $\left(C_{\mathrm{o}}=200 \mathrm{ppm}\right)$ at $\mathrm{pH}=2$. Fig. 18 shows that the adsorption of methyl orange was extremely fast in the first $30 \mathrm{~min}$, then progressively decreased within increasing contact time until 90 min was reached. Equilibrium was attained after 90 min of contact time, and there was no additional growth in sorption capacity with further increase in contact time. From these results, the equilibrium time in the adsorption experiments was taken as $90 \mathrm{~min}$.

Numerous steps were used to observe the adsorption kinetics controlling sorption processes like diffusion control, chemical reaction and mass transfer. Pseudo $1^{\text {st }}$ order and pseudo $2^{\text {nd }}$ order models were used for MO adsorption over modified and unmodified Cr-MIL-101. The similarity between the predicted values and experimental data was expressed by the correlation coefficients $R^{2} .{ }^{84}$ The formula for the pseudo $1^{\text {st }}$ order kinetic model is given by eqn (1):

$$
\log \left(q_{\mathrm{e}}-q_{t}\right)=\log \left(q_{\mathrm{e}}\right)-\left(\frac{k_{1}}{2.303}\right) t
$$
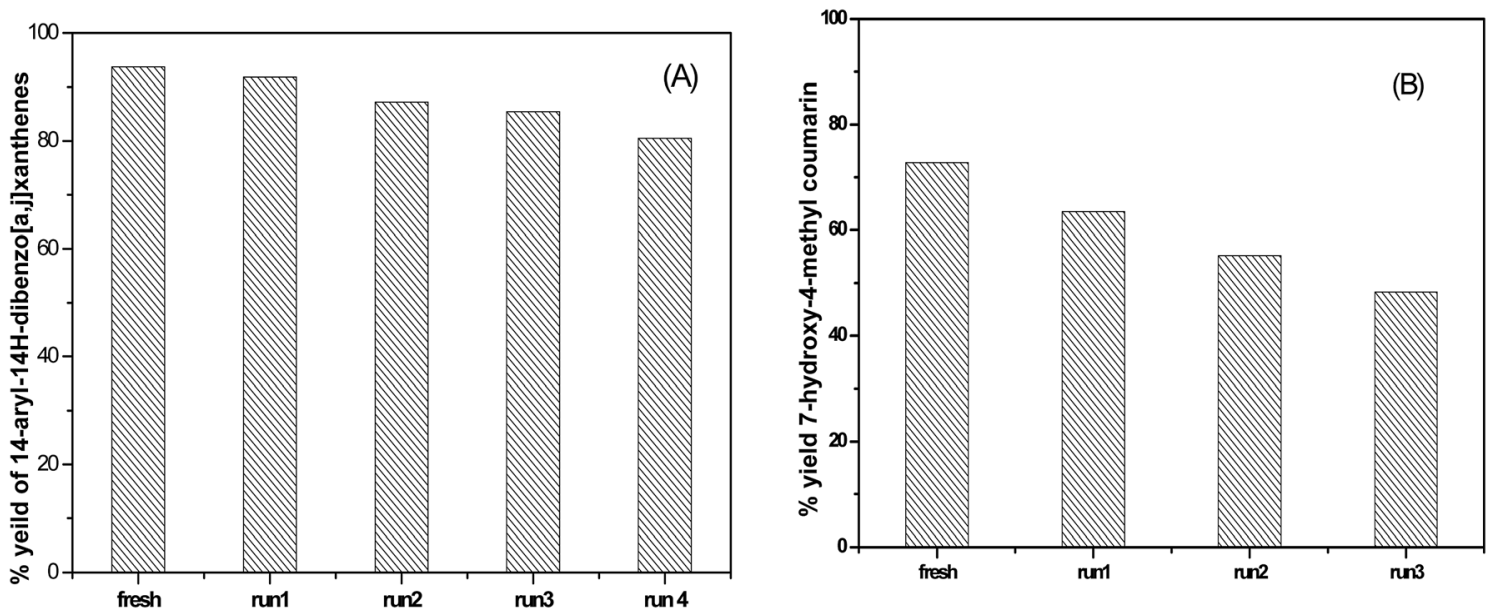

Fig. 15 The reusability of 55\% SA-MIL-101 in the synthesis of (A) 14-phenyl-14H-dibenzo [a,j] xanthene and (B) 7-hydroxy-4-methylcoumarin. 


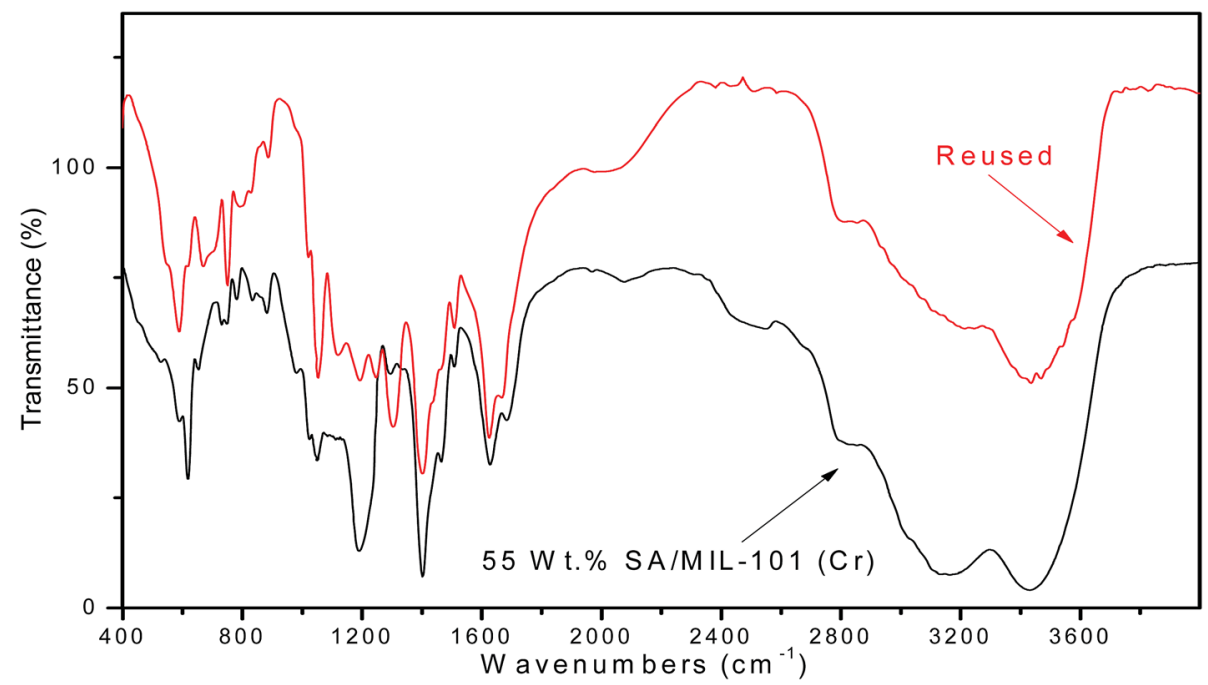

Fig. 16 FT-IR spectra of fresh and recovered 55\% sulfamic acid/MIL-101 (Cr).

where $q_{t}\left(\mathrm{mg} \mathrm{g}^{-1}\right)$ acts as the adsorption capacity of MO at any time $(t)$ and $q_{\mathrm{e}}\left(\mathrm{mg} \mathrm{g}^{-1}\right)$ is the adsorption capacity at equilibrium time, and $k_{1}\left(\mathrm{~min}^{-1}\right)$ is the rate constant of the pseudo $1^{\text {st }}$ order adsorption. On the other hand, the pseudo $2^{\text {nd }}$ order kinetic model is expressed by eqn (2):

$$
\frac{t}{q_{t}}=\frac{1}{k_{2} q_{\mathrm{e}}^{2}}+\frac{t}{q_{\mathrm{e}}}
$$

where $K_{2}\left(\mathrm{~g}(\mathrm{mg} \mathrm{min})^{-1}\right)$ is the rate constant of the pseudo $2^{\text {nd }}$ order adsorption that could be calculated from the linear plot of $t / q_{t}$ against time. The evaluated kinetic parameters and correlation coefficients $\left(R^{2}\right)$ from the kinetic models are summarized in Table 3. The variance in the calculated $q_{\mathrm{m}}$ and theoretical $q_{\mathrm{e}}$ and low $R^{2}$ value indicate that the pseudo $1^{\text {st }}$ order was not adequate to describe the adsorption of methyl orange over modified and unmodified MIL-101. From another point of view, the pseudo $2^{\text {nd }}$ order model was considered the best-fit model in the description of methyl orange adsorption from aqueous solution. It is clear that the rate of adsorption of MO was largely controlled by chemical processes that mostly involve ion exchange. ${ }^{85}$

3.7.3 Effect of initial MO concentration and adsorption isotherms. All the modified and unmodified MIL-101 materials were very active for the methyl orange adsorption from aqueous solution. The adsorption capacities of methyl orange under these experimental conditions are summarized in Table 3. The MIL-101 materials modified by sulfamic acid had better adsorption capacity compared to pure Cr-MIL-101, which may be due to the comparatively high concentration of amine groups. As shown in Table 3, by increasing the numbers of amine groups the adsorption increased up to 70\% SA-MIL-101 then decreased; this decrease might be due to the accumulation of sulfamic acid on MIL-101 surface as XRD and TEM images indicate.

Previously, it was stated that the insertion of nitrogen- or oxygen-containing functional groups into carbon materials

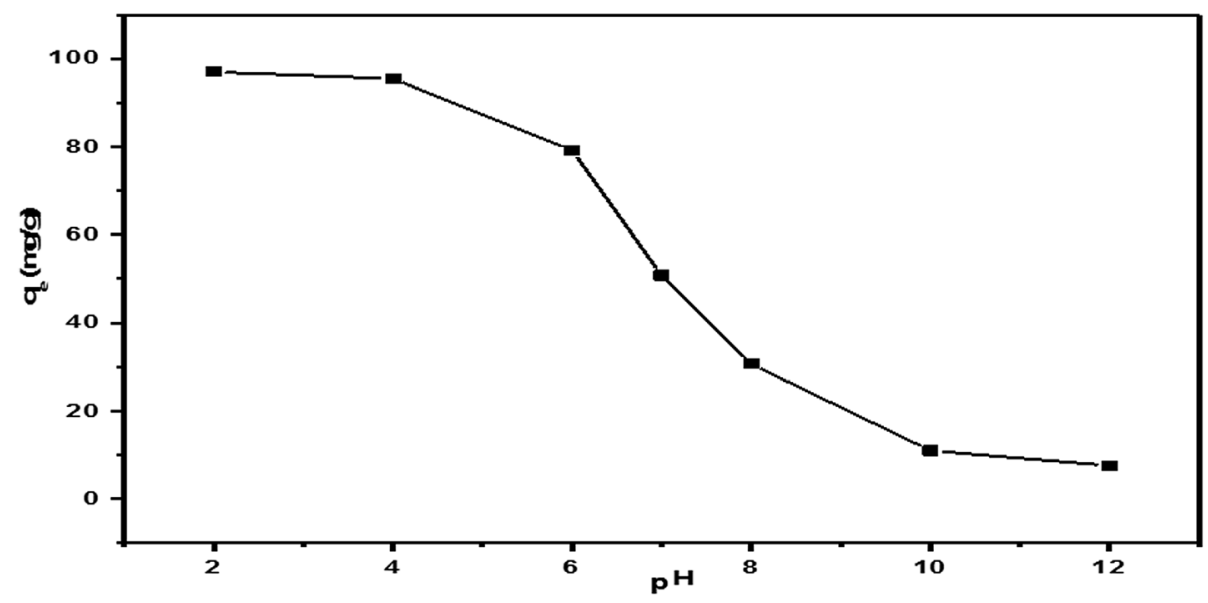

Fig. 17 The effect of the initial $\mathrm{pH}$ on the adsorption of $\mathrm{MO}$ on the $55 \% \mathrm{SA}-\mathrm{MIL}-101$ sample (adsorbent dosage $=50 \mathrm{mg}$, initial MO concentration $=100 \mathrm{ppm}$, solution volume $=50 \mathrm{~mL}$, temperature $=25^{\circ} \mathrm{C}$, contact time $=90 \mathrm{~min}$ ) . 


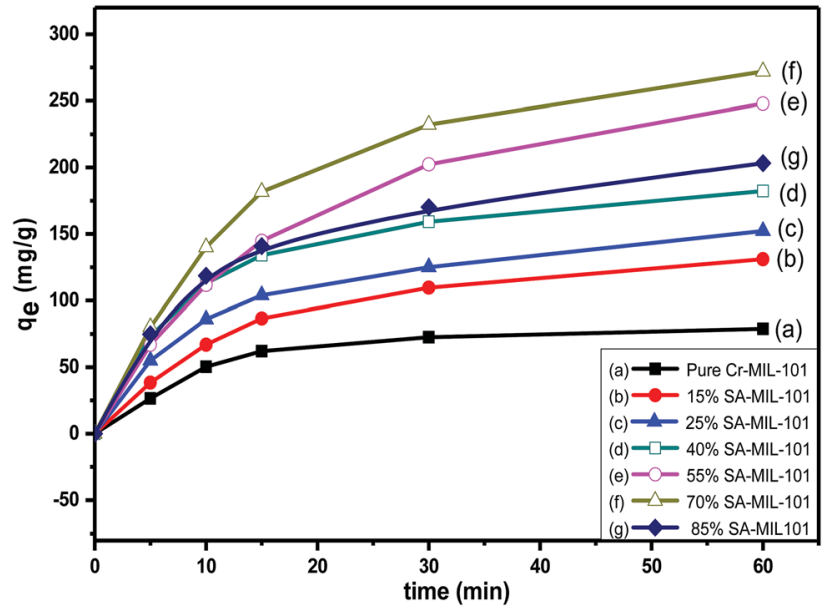

Fig. 18 The effect of contact time on MO removal using initial dye concentration $\left(C_{\circ}=200 \mathrm{ppm}\right)$ over different modified MIL-101 adsorbents.

might be helpful to enhance the adsorption capacity of materials for dyes. ${ }^{86,87}$ The introduced nitrogen- or oxygen-containing groups may coat the metal organic framework material with more basic sites and create more positively charged surfaces that could improve the interaction between anionic dye (MO) and MOFs though interactions like covalent bonding, electrostatic interaction, H-bonding, dipole-dipole interaction, and so on.

In order to detect the role of functional groups containing nitrogen in the adsorption capacity of pure and modified MIL101, the percentage removal of methyl orange at different initial concentrations was also investigated as shown in Fig. 19. The percentage removal of methyl orange was reduced progressively when the concentration of methyl orange increased from $25 \mathrm{ppm}$ to $500 \mathrm{ppm}$. At a moderately low concentration $(25 \mathrm{ppm})$, all adsorbents could totally remove methyl orange from aqueous solution. At a higher concentration of dye $(250 \mathrm{ppm}), 55 \%$ and $70 \%$ SA-MIL-101 could still cause the complete removal of dye. Evidently, both $55 \%$ and 70\% SA-MIL-101 material showed higher adsorption ability for MO removal compared to other adsorbents. This may be due to

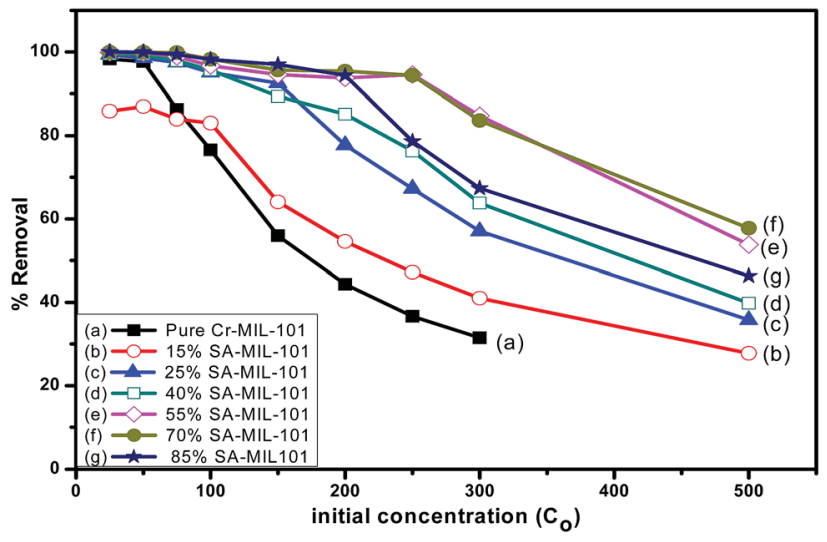

Fig. 19 The effect of methyl orange concentration on the adsorption performance over different adsorbents.

the high percentage of amine groups on the surface of the modified Cr-MIL-101.

The adsorption behavior of methyl orange on pure and modified MIL-101 was further studied, and two adsorption isotherm equations, the Langmuir and Freundlich isotherm models, were applied based on the adsorption equilibrium data.

Firstly, the Langmuir isotherm is given by eqn (3):

$$
\frac{C_{\mathrm{e}}}{q_{\mathrm{e}}}=\frac{1}{q_{\mathrm{m}} K_{\mathrm{L}}}+\frac{C_{\mathrm{e}}}{q_{\mathrm{m}}}
$$

where, $K_{\mathrm{L}}$ is the Langmuir adsorption constant $\left(\mathrm{L} \mathrm{mg}^{-1}\right), q_{\mathrm{m}}$ is the maximum monolayer adsorption capacity $\left(\mathrm{mg} \mathrm{g}^{-1}\right)$.

The Langmuir model assumes the formation of a monolayer over the surface of the adsorbent without attraction between adsorbed molecules. Maximum adsorption capacity $q_{\mathrm{m}}$ and Langmuir constants $K_{\mathrm{L}}$ values are listed in Table 4, which were calculated from the isotherm shown in Fig. 20. The main features of the Langmuir adsorption isotherm can be expressed in terms of the equilibrium parameter or separation factor $\left(R_{\mathrm{L}}\right)$, which is defined by eqn (4):

$$
R_{\mathrm{L}}=\frac{1}{\left(1+K_{\mathrm{L}} C_{\mathrm{o}}\right)}
$$

\begin{tabular}{|c|c|c|c|c|c|c|c|}
\hline Sample name & Experimental $q_{\mathrm{m}}\left(\mathrm{mg} \mathrm{g}^{-1}\right)$ & $R^{2}$ & $K_{1}\left(\min ^{-1}\right)$ & $q_{\mathrm{e}}\left(\mathrm{mg} \mathrm{g}^{-1}\right)$ & $R^{2}$ & $K_{2}\left(\mathrm{~g}(\mathrm{mg} \min )^{-1}\right)$ & $q_{\mathrm{e}}\left(\mathrm{mg} \mathrm{g}^{-1}\right)$ \\
\hline $15 \%$ SA-MIL- 101 at $150{ }^{\circ} \mathrm{C}$ & 143.5 & 0.9069 & 0.0137 & 67.7 & 0.9997 & 0.00059 & 147.9 \\
\hline $25 \%$ SA-MIL- 101 at $150{ }^{\circ} \mathrm{C}$ & 179.9 & 0.8909 & 0.0117 & 81.9 & 0.9999 & 0.00048 & 183.5 \\
\hline $40 \%$ SA-MIL- 101 at $150{ }^{\circ} \mathrm{C}$ & 200.8 & 0.8272 & 0.0104 & 70.1 & 0.9999 & 0.00070 & 201.6 \\
\hline $85 \%$ SA-MIL- 101 at $150{ }^{\circ} \mathrm{C}$ & 230.4 & 0.77325 & 0.0100 & 89.6 & 0.9997 & 0.00047 & 232.1 \\
\hline $55 \%$ SA-MIL- 101 at $250{ }^{\circ} \mathrm{C}$ & 188.7 & 0.9022 & 0.0139 & 91.9 & 0.9991 & 0.00037 & 196.1 \\
\hline $55 \%$ SA-MIL- 101 at $350{ }^{\circ} \mathrm{C}$ & 143.1 & 0.9192 & 0.0224 & 74.8 & 0.9996 & 0.00054 & 147.9 \\
\hline
\end{tabular}

Table 3 Kinetics parameters for the adsorption of methyl orange $\left(200 \mathrm{mg} \mathrm{L}^{-1}\right)$ with different loading content on MIL-101 
Table 4 Estimated constants from the Langmuir and Freundlich isotherms for MO adsorption by modified MIL-101

\begin{tabular}{|c|c|c|c|c|c|c|c|}
\hline Sample name & \multicolumn{4}{|c|}{ Langmuir isotherm } & \multicolumn{3}{|c|}{ Freundlich isotherm } \\
\hline $15 \%$ SA-MIL- 101 at $150{ }^{\circ} \mathrm{C}$ & 0.9954 & 0.0080 & 0.2478 & 143.5 & 0.8342 & 0.3488 & 21.704 \\
\hline $25 \%$ SA-MIL-101 at $150{ }^{\circ} \mathrm{C}$ & 0.9995 & 0.0076 & 0.2596 & 179.9 & 0.8975 & $0.2 ; 547$ & 54.347 \\
\hline $40 \%$ SA-MIL- 101 at $150{ }^{\circ} \mathrm{C}$ & 0.9994 & 0.0074 & 0.2665 & 200.8 & 0.9278 & 0.2584 & 60.234 \\
\hline $85 \%$ SA-MIL- 101 at $150{ }^{\circ} \mathrm{C}$ & 0.9964 & 0.0066 & 0.3014 & 230.4 & 0.9346 & 0.1677 & 99.289 \\
\hline $55 \%$ SA-MIL- 101 at $250{ }^{\circ} \mathrm{C}$ & 0.9992 & 0.0076 & 0.2619 & 188.7 & 0.9129 & 0.2330 & 62.127 \\
\hline $55 \%$ SA-MIL- 101 at $350{ }^{\circ} \mathrm{C}$ & 0.9968 & 0.0173 & 0.1132 & 143.1 & 0.9337 & 0.2283 & 42.729 \\
\hline
\end{tabular}

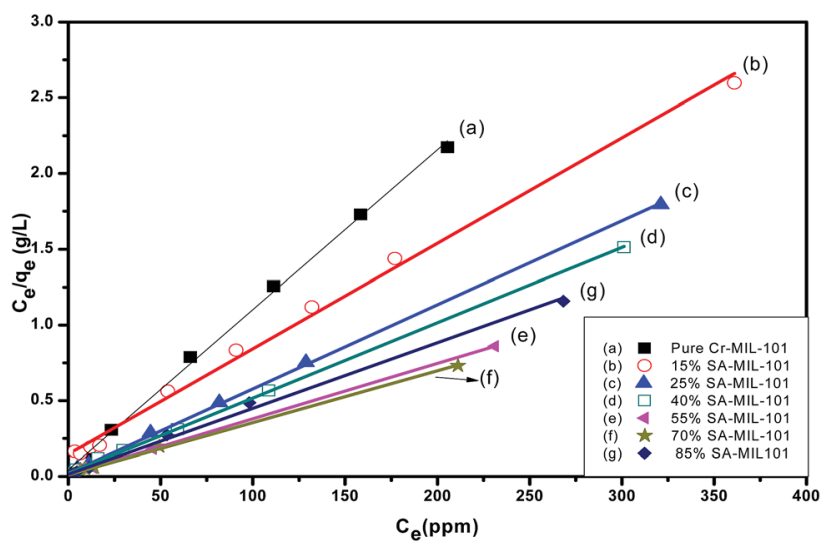

Fig. 20 Langmuir isotherms for the adsorption of MO onto modified and unmodified $\mathrm{Cr}$-MIL-101.

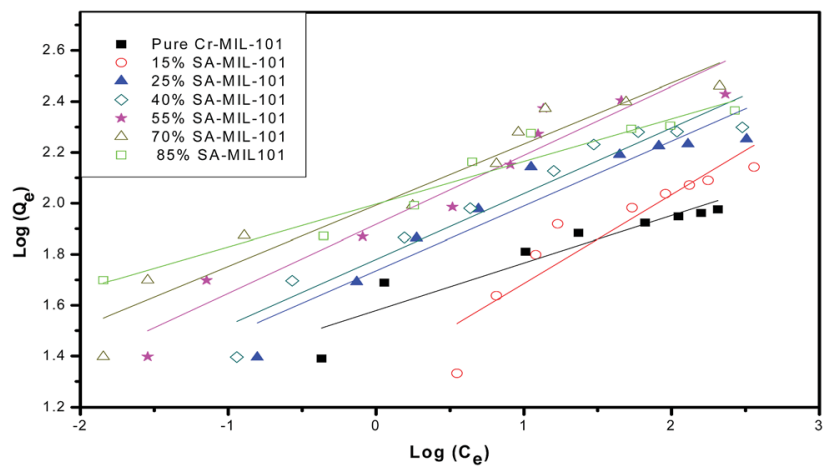

Fig. 21 Freundlich isotherms for the adsorption of $\mathrm{MO}$ onto modified and unmodified $\mathrm{Cr}$-MIL-101.

Table 5 Maximum adsorption capacities of methyl orange onto $\mathrm{N}$ containing adsorbents

\begin{tabular}{lll}
\hline Adsorbents & $q_{\mathrm{m}}\left(\mathrm{mg} \mathrm{g}^{-1}\right)$ & Ref. \\
\hline $\mathrm{NH}_{2}$-MWCNTs & 185.5 & 86 \\
NMC-3-800 & 202.4 & 88 \\
ED-MIL-101 & 160.0 & 21 \\
70\% SA-MIL-101 at $150{ }^{\circ} \mathrm{C}$ & 291.5 & This work
\end{tabular}

where $C_{\mathrm{o}}\left(\mathrm{mg} \mathrm{L}^{-1}\right)$ is the highest initial dye concentration. The value of $R_{\mathrm{L}}$ indicates that the type of isotherm can be unfavorable $\left(R_{\mathrm{L}}>1\right)$, linear $\left(R_{\mathrm{L}}=1\right)$, favorable $\left(0<R_{\mathrm{L}}<1\right)$ or irreversible $\left(R_{\mathrm{L}}=0\right) .{ }^{88}$ From Table 4 , all values of $R_{\mathrm{L}}$ were found between 0 and 1 , which demonstrates that methyl orange adsorption from water was favorable over all modified and pure MIL-101 samples.

Secondly, the surface heterogeneity was examined by the Freundlich model, which is given by eqn (5):

$$
\log q_{\mathrm{e}}=\frac{1}{n} \log C_{\mathrm{e}}+\log K_{\mathrm{F}}
$$

where $n$ is the adsorption intensity and $K_{\mathrm{F}}$ is the Freundlich constant related to the adsorption capacity, calculated from the fitted isotherms as shown in Fig. 21. The estimated values of $K_{\mathrm{F}}$ and $1 / n$ are represented in Table 4 . The slope $(1 / n)$ was used to determine the surface heterogeneity, which ranged from zero to one; the heterogeneity is high if the slope value is closer to zero. ${ }^{89}$ The values of $K_{\mathrm{F}}$ and $1 / n$ obtained in this study show that methyl orange adsorption over MIL-101 modified with sulfamic acid was favored by positive cooperative binding and was heterogeneous in nature. From Table 4, it is evident that the Langmuir model is the more appropriate model for describing the adsorption process due to its high correlation coefficients $\left(R^{2}\right)$ relative to the ones obtained from the Freundlich model.

From Table 4, the maximum adsorption capacity of methyl orange over the $70 \%$ SA-MIL-101 sample calcined at $150{ }^{\circ} \mathrm{C}\left(q_{\mathrm{m}}\right)$ is $291.5 \mathrm{mg} \mathrm{g}^{-1}$. A comparison of the maximum adsorption capacity $q_{\mathrm{m}}$ values for methyl orange on $70 \%$ SA-MIL-101 with previously reported $\mathrm{N}$-containing adsorbents is summarized in Table 5, which indicates that modified MIL-101 has great potential for methyl orange removal from water. It is obvious that the modified MIL-101 samples used in this work are exceptional adsorbent materials for the removal of dyes from wastewater.

\section{Conclusions}

In this study, a series of sulfamic acid-functionalized Cr-MIL101 catalysts was prepared for the first time via a facile impregnation method and characterized by various techniques. We demonstrated that Cr-MIL-101 has particle size of about 
300-500 nm and a crystalline structure. The modification of CrMIL-101 by sulfamic acid crystals progressively increased the surface acidity and Brønsted/Lewis acid ratio up to $55 \mathrm{wt} \%$ SA loading. The catalytic performance of SA/MIL-101 catalysts was examined in the synthesis xanthenes and coumarin derivatives. The catalytic performance was maximum at $55 \mathrm{wt} \%$ sulfamic acid loading. The decrease in the catalytic activity at higher loading ( $>55 \mathrm{wt} \%$ ) may be due to the decrease in acid strength and $\mathrm{B} / \mathrm{L}$ ratio. The existence of small amounts of reachable basic sites, like N-containing functional groups on the surface of SA/ MIL-101 materials, plays a great role in influencing the adsorption activity of methyl orange. The adsorption isotherms were well fitted to the Langmuir equation and the adsorption capacity of SA/MIL-101 reached $291 \mathrm{mg} \mathrm{g}^{-1}$ for the $70 \%$ SA/MIL101 sample.

\section{Conflicts of interest}

There are no conflicts to declare.

\section{References}

1 D. Zhao and K. Ding, ACS Catal., 2013, 3, 928-944.

2 V. Guillerm, D. Kim, J. F. Eubank, R. Luebke, X. Liu, K. Adil, M. S. Lah and M. Eddaoudi, Chem. Soc. Rev., 2014, 43, 61416172.

3 H. C. Zhou, J. R. Long and O. M. Yaghi, Chem. Rev., 2012, 112, 673-674.

4 C. Wang, D. Liu and W. Lin, J. Am. Chem. Soc., 2013, 135, 13222-13234.

5 D. Farrusseng, S. Aguado and C. Pinel, Angew. Chem., Int. Ed., 2009, 48, 7502-7513.

6 L. J. Murray, M. Dinca and J. R. Long, Chem. Soc. Rev., 2009, 38, 1294-1314.

7 M. D. Allendorf, C. A. Bauer, R. K. Bhakta and R. J. T. Houk, Chem. Soc. Rev., 2009, 38, 1330-1352.

8 J. Y. Lee, O. K. Farha, J. Roberts, K. A. Scheidt, S. T. Nguyen and J. T. Hupp, Chem. Soc. Rev., 2009, 38, 1450-1459.

9 A. Corma, H. García and F. X. L. Xamena, Chem. Rev., 2010, 110, 4606-4655.

10 F. Gandara, H. Furukawa, S. Lee and O. M. Yaghi, J. Am. Chem. Soc., 2014, 136, 5271-5274.

11 G. Blaniţa, M. Streza, M. D. Lazar and D. Lupu, Int. J. Hydrogen Energy, 2017, 42, 3064-3077.

12 Z. Dou, J. Yu, Y. Cui, Y. Yang, Z. Wang, D. Yang and G. Qian, J. Am. Chem. Soc., 2014, 136, 5527-5530.

13 M. G. Campbell and M. Dinca, Sensors, 2017, 17, 1108.

14 L. T. L. Nguyen, K. K. A. Le, H. X. Truong and N. T. S. Phan, Catal. Sci. Technol., 2012, 2, 521-528.

15 C. K. Brozek, L. Bellarosa, T. Soejima, T. V. Clark, N. Lopez and M. Dinca, Chem.-Eur. J., 2014, 20, 6871-6874.

16 D. Cunha, M. Ben Yahia, S. Hall, S. R. Miller, H. Chevreau, E. Elkaim, G. Maurink, P. Horcajada and C. Serre, Chem. Mater., 2013, 25, 2767-2776.

17 D. Tian, Y. Li, R. Y. Chen, Z. Chang, G. Y. Wang and X. H. Bu, J. Mater. Chem. A, 2014, 2, 1465-1470.
18 J. Kim, Y. R. Lee and W. S. Ahn, Chem. Commun., 2013, 49, 7647-7649.

19 R. B. Ferreira, P. M. Scheetz and A. L. B. Formiga, RSC Adv., 2013, 3, 10181-10184.

20 Y. Fang, G. Zhao, W. Dai, L. Ma and N. Ma, Microporous Mesoporous Mater., 2017, 251, 51-57.

21 A. Demessence, P. Horcajada, C. Serre, C. Boissiere, D. Grosso, C. Sanchez and G. Ferey, Chem. Commun., 2009, 46, 7149-7151.

22 D. Ma, B. Li, K. Liu, X. Zhang, W. Zou, Y. Yang, G. Li, Z. Shi and S. Feng, J. Mater. Chem. A, 2015, 3, 23136-23142.

23 I. E. Ertas, M. Gulcan, A. Bulut, M. Yurderi and M. Zahmakiran, Microporous Mesoporous Mater., 2016, 226, 94-103.

24 G. Akiyama, R. Matsuda, H. Sato, M. Takata and S. Kitagawa, Adv. Mater., 2011, 23, 3294-3297.

25 Y. D. Zang, J. Shi, F. M. Zhang, Y. J. Zhong and W. D. Zhu, Catal. Sci. Technol., 2013, 3, 2044-2049.

26 L. Bromberg, Y. Diao, H. Wu, S. A. Speakman and T. A. Hatton, Chem. Mater., 2012, 24, 1664-1675.

27 W. Du, G. Chen, R. Nie, Y. Li and Z. Hou, Catal. Commun., 2013, 41, 56-59.

28 S. M. Cohen, Chem. Rev., 2012, 112, 970-1000.

29 M. G. Goesten, J. J. Alcaniz, E. V. R. Fernandez, K. Gupta, E. Stavitski, H. V. Bekkum, J. Gascon and F. Kapteijn, J. Catal., 2011, 281, 177-187.

30 Y. D. Zang, J. Shi, X. M. Zhao, L. C. Kong, F. M. Zhang and Y. J. Zhong, React. Kinet., Mech. Catal., 2013, 109, 77-89.

31 D. Jiang, L. L. Keenan, A. D. Burrows and K. J. Edler, Chem. Commun., 2012, 48, 12053-12055.

32 A. Rostami and A. Yari, J. Iran. Chem. Soc., 2012, 9, 489-493.

33 A. Rostami and J. Akradi, Chin. Chem. Lett., 2011, 22, 13171320.

34 A. A. Napoleon and F. R. Khan, Med. Chem. Res., 2014, 23, 4749-4760.

35 K. M. Naidu, B. S. Krishna, M. A. Kumar, P. Arulselvan, S. I. Khalivulla and O. Lasekan, Molecules, 2012, 17, 75437555.

36 R. M. Kalla, M. Akkarapall and H. Osman, J. Drug Metab. Toxicol., 2014, 5, 1-7.

37 A. B. Ormond and H. S. Freeman, Materials, 2013, 6, 817840.

38 D. S. Pellosi, B. M. Estevao, J. Semensatoa, D. Severinob, M. S. Baptistab, M. J. Politi, N. Hiokaa and W. Caetanoa, J. Photochem. Photobiol., A, 2012, 247, 8-15.

39 S. Q. Zhang and W. B. Euler, Sens. Actuators, B, 2016, 225, 553-562.

40 G. Harichandran, S. D. Amalraj and P. Shanmugam, J. Mol. Catal. A: Chem., 2014, 392, 31-38.

$41 \mathrm{~J}$. Mondal, M. Nandi, A. Modak and A. Bhaumik, J. Mol. Catal. A: Chem., 2012, 363-364, 254-264.

42 Z. K. Jaberi and M. Keshavarzi, Chin. Chem. Lett., 2010, 21, 547-549.

43 F. Rashedian, D. Saberib and K. Niknam, J. Chin. Chem. Soc., 2010, 57, 998-1006.

44 F. Shirini and N. G. Khaligh, Dyes Pigm., 2012, 95, 789-794. 
45 M. B. Halli, R. B. Sumathi and M. Kinni, Spectrochim. Acta, Part A, 2012, 99, 46-56.

46 S. Emami and S. Dadashpour, Eur. J. Med. Chem., 2015, 102, 611-630.

47 S. A. El-Hakam, S. E. Samra, S. M. El-Dafrawy, A. A. Ibrahim and R. S. Salama, Int. J. Mod. Chem., 2013, 5(1), 55-70.

48 A. I. Ahmed, S. A. El-Hakam, A. S. Khder and W. S. Abo ElYazeed, J. Mol. Catal. A: Chem., 2013, 366, 99-108.

49 A. I. Ahmed, A. A. El-Khouly and Y. S. Samy, Int. J. Mod. Chem., 2013, 5(2), 87-100.

50 M. M. Ayad and A. Abu El-Nasr, J. Phys. Chem. C, 2010, 114(34), 14377-14383.

51 L. Zhou, C. Gao and W. Xu, ACS Appl. Mater. Interfaces, 2010, 2(5), 1483-1491.

52 S. Chen, J. Zhang, C. Zhang, Q. Yue, Y. Li and C. Li, Desalination, 2010, 252, 149-156.

53 E. Haque, J. E. Lee, I. T. Jang, Y. K. Hwang, J. Chang, J. Jegal and S. H. Jhung, J. Hazard. Mater., 2010, 181, 535-542.

54 L. Obeid, A. Bée, D. Talbot, S. B. Jaafar, V. Dupuis, S. Abramson, V. Cabuil and M. Welschbillig, J. Colloid Interface Sci., 2013, 410, 52-58.

55 X. Li, Y. Mao, K. Leng, G. Ye, Y. Sun and W. Xu, Microporous Mesoporous Mater., 2017, 254, 114-120.

$56 \mathrm{X} . \mathrm{Hu}, \mathrm{Y} . \mathrm{Lu}$, F. Dai, C. Liu and Y. Liu, Microporous Mesoporous Mater., 2013, 170, 36-44.

57 S. Brunauer, P. H. Emmett and E. Teller, J. Am. Chem. Soc., 1938, 60, 309-319.

58 E. P. Barrett, L. G. Joyner and P. P. Halenda, J. Am. Chem. Soc., 1951, 73, 373-380.

59 A. I. Ahmed, S. A. El-Hakam, M. A. Abd Elghany and W. S. Abo El-Yazeed, Appl. Catal., A, 2011, 407, 40-48.

60 Y. Jin, J. Shi, F. Zhang, Y. Zhong and W. Zhu, J. Mol. Catal. A: Chem., 2014, 383-384, 167-171.

61 R. Fazaeli, H. Aliyan, M. Moghadam and M. Masoudinia, J. Mol. Catal. A: Chem., 2013, 374-375, 46-52.

62 B. Kannan, P. R. Seshadri, P. Murugakoothan and K. Ilangovan, Indian J. Sci. Technol., 2013, 6, 4357-4361.

63 R. A. Gharde and D. T. Chunarkar, International Journal of Advanced Research in Computer Engineering \& Technology, 2012, 1, 230-233.

64 M. Anbia and V. Hoseini, J. Nat. Gas Chem., 2012, 21, 339343.

65 X. Liu, H. Li, H. Pan, H. Zhang, S. Huang, K. Yang, W. Xue and S. Yang, J. Energy Chem., 2016, 25, 523-530.

66 L. Qin, Z. Li, Z. Xu, X. Guo and G. Zhang, Appl. Catal., B, 2015, 179, 500-508.
67 G. Chen, S. Wu, H. Liu, H. Jiang and Y. W. Li, Green Chem., 2013, 15, 230-235.

68 E. Rafiee, M. Joshaghani, S. Eavania and S. Rashidzadeh, Green Chem., 2008, 10, 982-989.

69 A. S. Khder, H. M. A. Hassan and M. S. El-Shall, Appl. Catal., A, 2014, 487, 110-118.

70 A. I. Ahmed, S. A. El-Hakam, S. E. Samra, A. A. EL-Khouly and A. S. Khder, Colloids Surf., A, 2008, 317, 62-70.

71 H. M. Altass and A. S. Khder, J. Mol. Catal. A: Chem., 2016, 411, 138-145.

72 C. L. Hill and C. M. P. McCarthy, Coord. Chem. Rev., 1995, 143, 407-455.

73 J. Safaei-Ghomi and M. A. Ghasemzadeh, Chin. Chem. Lett., 2012, 23, 1225-1229.

74 B. Rajitha, B. S. Kumar, Y. T. Reddy, P. N. Reddy and N. Sreenivasulu, Tetrahedron Lett., 2005, 46, 8691-8693.

75 B. Karami, K. H. Eskandari, S. Gholipour and M. Jamshidi, Org. Prep. Proced. Int., 2013, 45, 220-226.

76 B. Das, J. Kashanna, R. A. Kumar and P. Jangili, Synth. Commun., 2012, 42, 2876-2884.

77 S. Palaniappan and R. C. Shekhar, J. Mol. Catal. A: Chem., 2004, 209, 117-124.

78 A. J. Hoefnagel, E. A. Gunnewegh, R. S. Downing and H. v. Bekkum, J. Chem. Soc., Chem. Commun., 1995, 225-226.

79 S. Kim, D. Kang, C. H. Lee and P. H. Lee, J. Org. Chem., 2012, 77, 6530-6537.

80 W. Song, B. Gao, X. Xu, L. Xing, S. Han, P. Duan, W. Song and R. Jia, Bioresour. Technol., 2016, 210, 123-130.

81 M. V. Subbaiah and D. S. Kim, Ecotoxicol. Environ. Saf., 2016, 128, 109-117.

82 K. Fouad and B. Omar el Farouk, Desalin. Water Treat., 2015, 53, 3711-3723.

83 D. H. K. Reddy and S. M. Lee, Adv. Colloid Interface Sci., 2013, 201-202, 68-93.

84 R. Lafi and A. Hafiane, J. Taiwan Inst. Chem. Eng., 2016, 58, 424-433.

85 J. R. Deka, C. L. Liu, T. H. Wang, W. C. Chang and H. M. Kao, J. Hazard. Mater., 2014, 278, 539-550.

86 Y. Liu, G. Cui, C. Luo, L. Zhang, Y. Guo and S. Yan, RSC Adv., 2014, 4, 55162-55172.

87 J. Ma, F. Yu, L. Zhou, L. Jin, M. Yang, J. Luan, Y. Tang, H. Fan, Z. Yuan and J. Chen, ACS Appl. Mater. Interfaces, 2012, 4, 5749-5760.

88 H. Li, N. An, G. Liu, J. Li, N. Liu, M. Jia, W. Zhang and X. Yuan, J. Colloid Interface Sci., 2016, 466, 343-351.

89 K. Y. Foo and B. H. Hameed, Chem. Eng. J., 2010, 156, 2-10. 